\title{
Flora vascular do Parque Estadual Carlos Botelho, São Paulo, Brasil
}

\author{
Renato Augusto Ferreira de Lima ${ }^{1,7}$, Vinícius Antonio de Oliveira Dittrich ${ }^{2}$, \\ Vinícius Castro de Souza ${ }^{3}$, Alexandre Salino ${ }^{4}$, Tiago Böer Breier ${ }^{5}$ \& Osny Tadeu de Aguiar ${ }^{6}$ \\ ${ }^{1}$ Programa de Pós-graduação em Ecologia, Instituto de Biociências, Universidade de São Paulo - USP, \\ Rua do Matão, travessa 14, 321, CEP 05508-090, São Paulo, SP, Brasil \\ ${ }^{2}$ Departamento de Botânica, Instituto de Ciências Biológicas, Universidade Federal de Juiz de Fora - UFJF, \\ Rua José Lourenço Kelmer, s/n, Campus Universitário, CEP 36036-900, Juiz de Fora, MG, Brasil \\ ${ }^{3}$ Departamento de Ciências Biológicas, Escola Superior de Agricultura 'Luiz de Queiroz', \\ Universidade de São Paulo - ESALQ-USP, Av. Pádua Dias, 11, CEP 13418-900, Piracicaba, SP, Brasil \\ ${ }^{4}$ Departamento de Botânica, Instituto de Ciências Biológicas, Universidade Federal de Minas Gerais - UFMG, \\ Av. Antônio Carlos, 6627, CEP 31270-901, Belo Horizonte, MG, Brasil \\ ${ }^{5}$ Departamento de Silvicultura, Instituto de Florestas, Universidade Federal Rural do Rio de Janeiro - UFRRJ, \\ Rod. BR 465, Km 07, CEP 23890-000, Seropédica, RJ, Brasil \\ ${ }^{6}$ Divisão de Dasonomia, Instituto Florestal - IF, Secretaria do Meio Ambiente, \\ Rua do Horto, 931, CEP 02377-000, São Paulo, SP, Brasil \\ ${ }^{7}$ Autor para correspondência: Renato Augusto Ferreira de Lima, e-mail: raflima@usp.br
}

LIMA, R.A.F., DITTRICH, V.A.O., SOUZA, V.C., SALINO, A., BREIER, T.B. \& AGUIAR, O.T. Vascular flora of the Carlos Botelho State Park, São Paulo, Brazil. Biota Neotrop. 11(4): http://www.biotaneotropica.org.br/ v11n4/en/abstract?inventory+bn01211042011

\begin{abstract}
Located in the Serra de Paranapiacaba, South of São Paulo State, the Carlos Botelho State Park (PECB) shelters more than 37,000 ha of Atlantic Forest in one of the most important and large remnants of this Biome in Brazil. In the Park the Montane and Submontane rain forests are the predominant types of forests. Aiming to organize the available floristic information and to orient future surveys, this study presents the list of native vascular species of the PECB forests. Besides authors' personal collections, more than 3,900 records since 1967 were compiled. Coming from different sources of information, these records were checked for the presence of botanical synonyms and new combinations. A total of 1,143 species belonging to 528 genera and 140 families were listed (other 63 species were not included because they were non-native or of doubtful occurrence/determination). There was a great richness of Myrtaceae, Orchidaceae, Fabaceae, Asteraceae, Melastomataceae, Lauraceae, Rubiaceae and Bromeliaceae. Although high species richness was found, the richness of herbs, lianas and epiphytes are certainly underestimated and future surveys will add many species to the list presented here. In addition, more than 60 endangered species were found, mainly among the Myrtaceae, Lauraceae and Gesneriaceae families. Therefore, these results put the PECB among the most species-rich conservation units of São Paulo state with great relevance to national conservancy of plant diversity.
\end{abstract}

Keywords: Atlantic Forest, endangered species, floristics, Neotropics, species richness.

LIMA, R.A.F., DITTRICH, V.A.O., SOUZA, V.C., SALINO, A., BREIER, T.B. \& AGUIAR, O.T. Flora vascular do Parque Estadual Carlos Botelho, São Paulo, Brasil. Biota Neotrop. 11(4): http://www.biotaneotropica.org. br/v11n4/pt/abstract?inventory+bn01211042011

Resumo: Localizado na Serra de Paranapiacaba, sul do Estado de São Paulo, o Parque Estadual Carlos Botelho (PECB) abriga mais de 37.000 ha de Floresta Atlântica em um dos remanescentes mais importantes e extensos deste Bioma no Brasil. No Parque, predomina a Floresta Ombrófila Densa Montana e Submontana. Com o objetivo de organizar as informações florísticas disponíveis e direcionar futuros levantamentos, este estudo apresenta a lista de espécies vasculares nativas das florestas do PECB. Além de coletas pessoais dos autores, foram compilados mais de 3.900 registros citados desde 1967. Provindos de diferentes fontes de informação, estes registros foram checados para verificar a presença de sinonímias botânicas e novas combinações. Foi listado um total de 1.143 espécies vasculares pertencentes a 140 famílias e 528 gêneros (outras 63 espécies não foram incluídas por serem exóticas ou de ocorrência/identificação duvidosa). Houve grande riqueza de Myrtaceae, Orchidaceae, Fabaceae, Asteraceae, Melastomataceae, Lauraceae, Rubiaceae e Bromeliaceae. Apesar da alta riqueza de espécies, a riqueza de ervas, epífitos e lianas está certamente subestimada no Parque, de modo que futuros levantamentos certamente incluirão várias espécies na lista apresentada aqui. Adicionalmente, foram encontradas mais de 60 espécies com algum grau de ameaça de extinção, principalmente entre as famílias Myrtaceae, Lauraceae e Gesneriaceae. Assim, os resultados encontrados colocam o PECB entre as unidades de conservação com maior riqueza de espécies no Estado de São Paulo, com grande importância nacional para a conservação de espécies de plantas.

Palavras-chave: Floresta Atlântica, espécies ameaçadas, florística, Neotrópico, riqueza de espécies. 


\section{Introdução}

Dentre os diferentes biomas do globo, a Floresta Atlântica (sensu Oliveira-Filho \& Fontes 2000) é mundialmente conhecida por dois motivos contrastantes. Ela possui uma das maiores diversidades de espécies do planeta (e.g. Martini et al. 2007), que é acompanhada por um dos maiores índices de endemismo de espécies (Myers et al. 2000). Ao mesmo tempo, ela é um dos biomas mais devastados e ameaçados do mundo, reduzida a menos de $16 \%$ de sua extensão original (Ribeiro et al. 2009). Este fato é alarmante visto que este bioma já foi a segunda maior formação florestal tropical da América do Sul (Morellato \& Haddad 2000) e se torna ainda mais preocupante, pois ainda há muito a ser descoberto sobre sua real diversidade de espécies (Shepherd 2000). Por estes motivos, a Floresta Atlântica foi eleita um dos cinco mais importantes hotspots da biodiversidade do planeta (Myers et al. 2000).

Originalmente, a Floresta Atlântica se estendia por toda a costa Leste e Sul do Brasil, adentrando para o interior no Sul e Sudeste do país e atingindo o sudeste do Paraguai e o nordeste da Argentina. Hoje, fragmentos florestais extensos e bem conservados são raros (Morellato \& Haddad 2000, Ribeiro et al. 2009) e se concentram principalmente nas encostas íngremes da Serra do Mar dos estados do Rio de Janeiro, São Paulo, Santa Catarina e Paraná, onde a dificuldade de mecanização impôs restrições à agricultura (Viana \& Tabanez 1996). Nestas áreas, unidades de conservação de proteção integral possuem um papel estratégico na conservação da biodiversidade remanescente, que deve ser estudada com urgência. A produção de inventários de espécies representa o primeiro passo para fornecer informações sobre a composição, diversidade e distribuição das espécies. Mesmo assim, são relativamente raros os exemplos de listas detalhadas de espécies de plantas em unidades de conservação na Floresta Atlântica (e.g. Barros et al. 1991, Lima \& Guedes-Bruni 1997, Mamede et al. 2001, Ziparro et al. 2005). A ocorrência de populações viáveis em unidades de conservação tem peso importante na conservação das espécies e é usada como um dos critérios para a definição do grau de ameaça de extinção (Mamede et al. 2007).

Como resultado da união de antigas Reservas Florestais do Estado, o Parque Estadual Carlos Botelho (PECB) foi criado em 1982 e hoje faz parte de um dos maiores remanescentes de Floresta Atlântica do Brasil (Ribeiro et al. 2009). Este remanescente é composto por outras importantes unidades de conservação, como os Parques Estaduais da Serra do Mar, Jurupará, Intervales e Turístico do Alto Ribeira, entre outras unidades de conservação. Nessa região do Estado de São Paulo predomina a Floresta Ombrófila Densa que é, muito provavelmente, a formação florestal que abriga a grande parte da biodiversidade da Floresta Atlântica. Por estes motivos, o PECB possui um papel estratégico na conservação da diversidade vegetal da Floresta Atlântica, do Brasil e do mundo.

Se comparado a outras unidades de conservação do estado (e talvez do Brasil), o PECB é uma unidade relativamente bem conhecida em relação a sua flora e vegetação, com vários projetos de pesquisa e levantamentos tendo sido desenvolvido recentemente no seu interior (e.g. Breier 2005). Por exemplo, o parque conta hoje com três grandes levantamentos (>5 ha) de árvores e arbustos (Aguiar 2003, Dias 2005, Rodrigues 2005). Assim, acreditamos haver conhecimento suficiente para produzir um checklist da flora do Parque. Portanto, este estudo apresenta uma lista de espécies do PECB com o intuito de prover informações sobre a riqueza e composição de espécies vasculares, e de fornecer diretrizes para futuras pesquisas e levantamentos florísticos no parque.

\section{Material e Métodos}

O PECB está localizado no sul do Estado de São Paulo, entre as coordenadas geográficas $24^{\circ} 06^{\prime} 55^{\prime \prime}$ e $24^{\circ} 14^{\prime} 41^{\prime \prime} \mathrm{S}$ e $47^{\circ} 47^{\prime} 18^{\prime \prime}$ e 48 07' 17' O (municípios de Sete Barras, São Miguel Arcanjo, Capão Bonito e Tapiraí). O Parque possui 37.644 ha e abrange um relevo montanhoso e escarpado, com altitudes entre 30 e $1.000 \mathrm{~m}$. A temperatura e precipitação anuais médias para a região mais baixa do PECB são de $22^{\circ} \mathrm{Ce} 1.600 \mathrm{~mm}$, respectivamente, não havendo déficit hídrico anual significativo (Rodrigues 2005). Não há estimativas publicadas para os mesmos parâmetros climáticos na parte alta do parque. A vegetação predominante do PECB é a Floresta Ombrófila Densa Atlântica Montana e Submontana sensu IBGE (Instituto... 1992) (Figura 1). Existem também trechos menores recobertos por Floresta Ombrófila Densa Alto Montana (áreas acima de 900-1000 m de altitude) e por Campos de Altitude, sobre solos rasos e pedregosos dos cumes mais altos. A Floresta Ombrófila Densa de Terras Baixas (sensu Instituto... 1992) também ocorre em áreas abaixo dos $50 \mathrm{~m}$. No PECB as formações florestais variam entre trechos bem conservados com dossel contínuo acima de $20 \mathrm{~m}$, até formações secundárias com dossel menor e mais aberto. Formações com a presença marcante de bambus lenhosos, em especial Guadua tagoara, também ocorrem no interior do Parque. Infelizmente, evidências da extração ilegal de palmito-juçara (Euterpe edulis) são comuns em várias áreas do PECB. Informações detalhadas sobre a estrutura e dinâmica da vegetação podem ser encontradas em vários estudos realizados no parque (e.g., Negreiros et al. 1995, Dias et al. 2000, Lima \& Moura 2006), principalmente em relação às árvores e arbustos nos trechos de Floresta Ombrófila Densa Montana e Submontana. Apenas os estudos de Breier (2005) e Udulutsch (2004), ambos num mesmo trecho de Floresta Ombrófila Densa Submontana, enfocaram os epífitos vasculares e as lianas lenhosas, respectivamente. Até o momento, nenhum levantamento direcionado foi realizado para a forma de vida herbácea terrestre.

Para a compilação da lista de espécies, foram consideradas apenas as espécies vasculares (pteridófitas, gimnospermas e angiospermas) ocorrentes em ambiente florestal. O termo florestal é empregado aqui para caracterizar as espécies que ocorrem sob ou sobre o dossel, em clareiras, ao longo de rios, em trechos de bambuzais, em borda de mata, em deslizes de terra ou mesmo às margens da rodovia que corta o Parque (SP-139). Várias fontes de informação foram usadas para a compilação da lista. Coletas realizadas pelos autores e ainda não incorporadas à lista de herbários consultados (ver lista abaixo) são citadas junto com o número de coleta de cada autor. Foram consultadas também as listas disponíveis nos estudos de Custódio-Filho et al. (1992), Moraes (1992), Negreiros et al. (1995), Dias et al. (2000), Nonato \& Windisch (2004), Lima \& Moura (2006), e Moraes (2007). Também foi consultado o levantamento realizado no parque em 1987 por Alwyn H. Gentry e colaboradores, publicado por Philips \& Miller (2002). Da mesma maneira, foi analisado o trabalho feito por Heinsdijk \& Campos (1967), mas com várias restrições devido à qualidade das identificações, feitas através de amostras de lenho. Finalmente, também foram incluídos alguns poucos registros de campo feitos pelos autores durante o período de compilação dos dados e por outros pesquisadores trabalhando no PECB. Esta fonte de informação correspondeu a uma pequena quantidade dos registros realizados e basicamente a espécies de fácil determinação em campo (e.g. Pteridium arachnoideum, Astrocaryum aculeatissimum, Lytocaryum hoehnei, Vriesea scalaris, Maprounea guianensis, Eriotheca pentaphylla, Gallesia integrifolia e Cecropia pachystachya).

Como fonte alternativa de informação, foi realizado um levantamento das espécies vasculares coletadas no PECB depositados em diferentes herbários nacionais e internacionais. Inicialmente, este levantamento foi realizado com o auxílio da rede speciesLink (Centro... 2008), no qual é possível consultar as coleções por município e localidade de coleta. A consulta foi realizada até Janeiro 


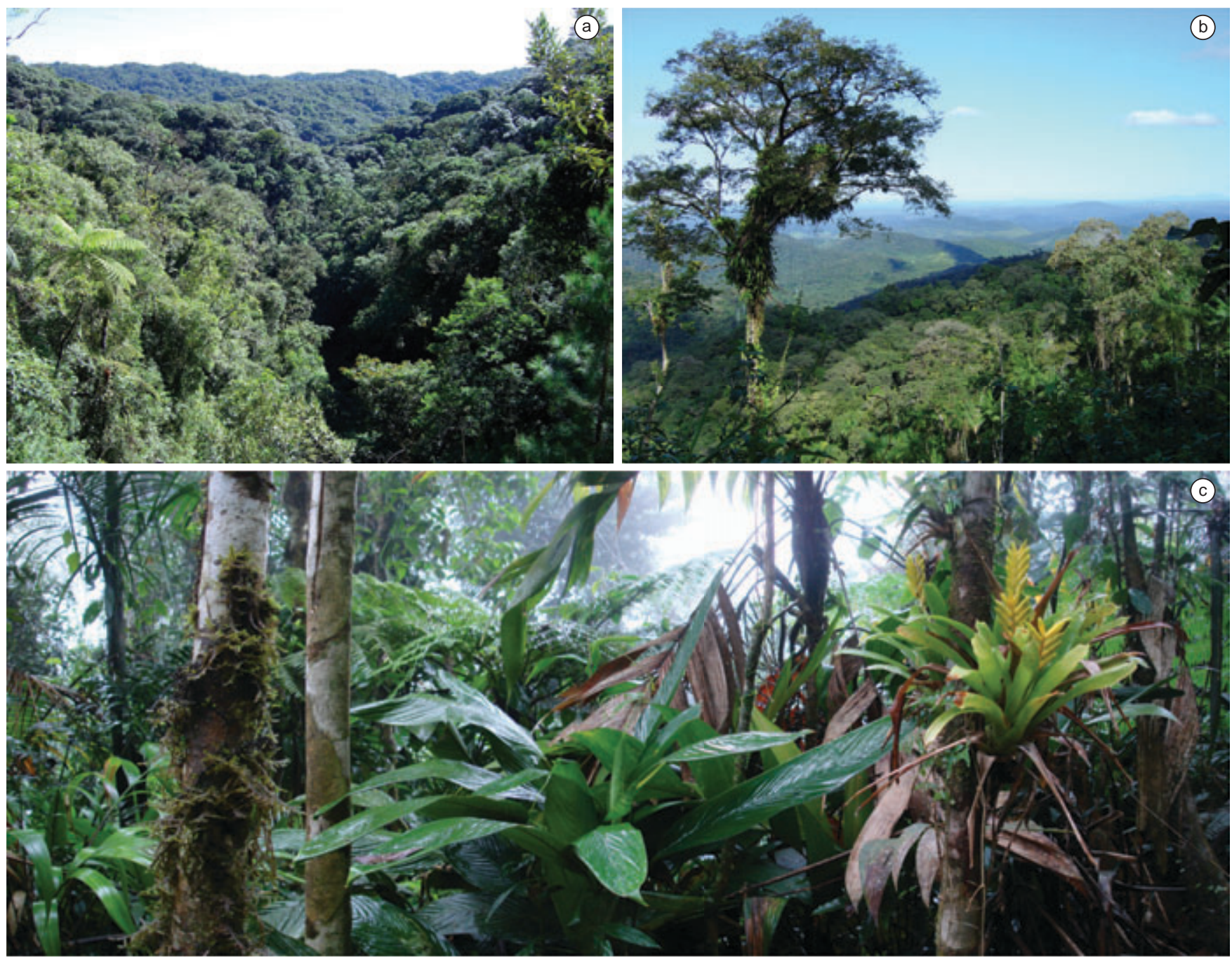

Figura 1. As duas principais fitofisionomias ocorrentes no Parque Estadual Carlos Botelho, São Paulo, Brasil. a) Floresta Ombrófila Densa Montana. b) Floresta Ombrófila Densa Submontana. c) vista interna da Floresta Ombrófila Densa Submontana. Fotos: a-b) R.A.F. Lima. c) T.B. Breier.

Figure 1. The two main forest types occurring in the Carlos Botelho State Park, São Paulo, Brazil. a) Montane Rain Forest. b) Submontane Rain Forest. c) inside-view of the Submontane Rain Forest. Photos: a-b) R.A.F. Lima. c) T.B. Breier.

de 2010, e encontrou materiais depositados nos seguintes herbários (siglas sensu Holmgren et al. 1990): ESA, HRCB, SP, SPF, SPSF, UEC, IAC, RB, MO e NY. Como alguns herbários não tinham informatizado totalmente suas coleções no período da busca, como o SP, o HRCB e o SPF, vale lembrar que importantes herbários não foram completamente avaliados. Foram consultados, mesmo que de maneira restrita, os materiais depositados em herbários até então não cadastrados na rede speciesLink: BHCB e MBM. Foram considerados apenas os materiais coletados dentro dos limites do parque. Ou seja, materiais coletados no parque podem não ter sido incluídos na listagem final por falta de detalhamento da localidade de coleta. De maneira geral, a inclusão de novas espécies foi feita através de materiais cuja identificação houvesse sido confirmada por especialistas.

Alguns critérios básicos foram adotados para gerar a lista final das espécies do PECB. Não foram considerados os indivíduos identificados em nível de família. Espécies identificadas em nível de gênero foram adicionadas à listagem apenas em duas circunstâncias: quando um trabalho de referência possuísse número de espécies do gênero superior ao número acumulado de espécies citadas pelos demais trabalhos; ou quando o gênero não houvesse sido listado em nenhum outro trabalho de referência. Indivíduos com identificação de espécie a confirmar (confers) foram considerados como uma citação a mais para a espécie sugerida para confirmação. Exceções foram feitas quando a espécie a confirmar se tratava de um gênero ainda não listado nos demais trabalhos. Adotou-se o mesmo critério para as espécies listadas como affinis.

A listagem foi organizada segundo a circunscrição em famílias proposta pelo Angiosperm Phylogeny Group-APG, versão III (2009) para as Angiospermas, por Moran (1995) para as licófitas e por Smith et al. (2006) para as monilófitas. Não se considerou separadamente as famílias Cordiaceae, Heliotropiaceae (inclusas em Boraginaceae) ou Peraceae (inclusa em Euphorbiaceae) cujo posicionamento ainda é incerto (Angiosperm... 2009). Contudo, consideraram-se os novos posicionamentos sugeridos para Myrsinaceae e Quiinaceae, posicionadas dentro de Primulaceae e Ochnaceae, respectivamente (Angiosperm... 2009). A grafia correta das espécies e autores foi checada através dos volumes da Flora Fanerogâmica do Estado de São Paulo (Wanderley et al. 2002, 2003, 2005, Melhem et al. 2007), e das bases de dados Tropicos (2009) e International Plant Names Index (2008). Recorreu-se a revisões recentes para determinar a presença de sinonímias botânicas e 
mudanças nomenclaturais, em especial, nos volumes já publicados da Flora Fanerogâmica do Estado de São Paulo (citado acima) e no site do World Checklist of Selected Plant Families (Royal... 2008). Para as famílias botânicas ainda não revisadas nestes volumes, a detecção de sinonímias e as revisões de nomenclatura dependeram da disponibilidade de literatura especializada e da participação de alguns especialistas. Portanto, é possível que, para algumas famílias, sinônimos possam ter sido incluídos devido à inexistência de revisões atuais ou devido ao desconhecimento destes materiais por parte dos autores.

Além da lista final de espécies, foi gerada uma lista à parte com os registros excluídos e o respectivo motivo da exclusão (espécie subespontânea, introduzida, binômio desconhecido, identificação ou ocorrência duvidosa). Para os registros inclusos na lista final, não foram realizadas revisões de identificação das espécies listadas nos trabalhos consultados, uma tarefa praticamente impossível. Contudo, caso uma dada espécie tivesse uma distribuição geográfica confirmada apenas para áreas muito distantes ou para formações vegetais muito diferentes das ocorrentes no PECB, a espécie foi citada apenas na lista de espécies excluídas. Após a conclusão da lista final, buscouse o grau de ameaça de extinção das espécies em nível mundial (International... 2002), nacional (Fundação Biodiversitas 2005) e estadual (Mamede et al. 2007). Em relação à distribuição espacial dos registros, informações sobre a ocorrência das espécies nas diferentes fitofisionomias do PECB foram escassas e variaram entre as diferentes fontes de informação consultada. A única e rudimentar informação de distribuição comum e disponível para quase todas as fontes de informação foi o município no qual a coleta ou trabalho foi realizado (São Miguel Arcanjo, Sete Barras, Capão Bonito ou Tapiraí). Assim, quaisquer análises sobre a distribuição das espécies no parque são limitadas.

\section{Resultados e Discussão}

Além dos registros e coletas realizadas pelos autores no PECB, foram obtidos 961 registros nos trabalhos publicados e 785 registros em herbário, provindos de mais de 2.500 vouchers (excluindo duplicatas entre herbários). A partir destes registros, foi listado um total de 1.143 espécies vasculares nativas (Apêndice 1), pertencentes a 528 gêneros e 140 famílias (Figura 2). Além das 14 espécies exóticas ou introduzidas citadas para o PECB, outras 63 espécies de ocorrência ou identificação duvidosas foram excluídas da lista final (Apêndice 2). Poucas espécies permaneceram com suas identificações incompletas $(2,2 \%)$. Foram 14 espécies determinadas em nível de gênero, duas com identificação affinis e nove com identificação a confirmar. Uma espécie de Rubiaceae (Sphinctanthus sp.) encontrada no município de Sete Barras (Floresta Ombrófila Densa Submontana) é provavelmente nova para o Estado de São Paulo e, talvez, para a ciência. Além deste total, sabe-se também da ocorrência de outras 11 espécies lianescentes no PECB (R.G. Udulutsch, comunicação pessoal), o que eleva a riqueza do parque a um total de 1.154 espécies. Há ainda várias coletas estéreis referentes aos estudos de Aguiar (2003) e Dias (2005) que podem ser novas ocorrências para o Parque, mas que não foram incluídas aqui por permaneceram sem identificação confiável, principalmente entre Myrtaceae e Lauraceae.

Os resultados encontrados mostram que o PECB está entre as unidades de conservação com maior riqueza de espécies do estado de São Paulo. No Parque Estadual da Serra do Mar, uma unidade de conservação bem mais extensa e heterogênea, foram listadas aproximadamente 1.200 espécies vasculares (valor inclui espécies de áreas não florestais-São Paulo (2006)). Barros et al. (1991) listaram 986 espécies de angiospermas para o Parque Estadual da Ilha do Cardoso (inclui espécies não florestais de restinga). Na Serra da Juréia, Mamede et al. (2001) citaram 756 espécies vasculares, enquanto que Kirizawa et al. (2007) listaram 997 espécies de angiospermas para a Reserva Biológica do Alto da Serra de Paranapiacaba. Adicionalmente, o PECB apresentou um número total de espécies e de famílias que é comparável a outras unidades de conservação neotropicais (Tabela 1). Mesmo com a grande variação de tamanho e de número de fitofisionomias amostradas entre estas unidades de conservação (além de algumas listas estarem certamente desatualizadas), pode-se afirmar que o PECB possui grande importância na conservação da diversidade de plantas no país.

Apesar dos resultados representarem uma boa amostra da riqueza de espécies vasculares do PECB, o número total de espécies em seu interior certamente está subestimado. Além de várias formas de vida estarem subamostradas, grande parte das coletas e estudos realizados está concentrada em áreas pequenas se comparado a extensão total do Parque. Grande parte das coletas, por exemplo, foi feita próxima à sede da unidade e em trechos ao longo da SP-139. Além disso, várias espécies encontradas no PECB foram citadas para apenas um estudo (Apêndice 1), sugerindo que outras espécies serão registradas caso levantamentos direcionados e/ou intensivos sejam conduzidos no Parque. Assim, baseado nas proporções de riqueza por hábito apresentadas por Gentry \& Dodson (1987) para florestas neotropicais e assumindo que a riqueza de árvores registrada é próxima ao real existente no parque, estimamos que a riqueza total do PECB seja de aproximadamente 1.500 espécies vasculares florestais. Claro que esse valor é meramente especulativo e impreciso, mas acreditamos que seja um valor bastante razoável frente ao atual grau de desconhecimento da flora do parque.

Tabela 1. Número total de espécies e de famílias em diferentes florestas neotropicais. Localidades: PECB = Parque Estadual Carlos Botelho (Brasil), REMC = Reserva Ecológica de Macaé de Cima (Brasil), Una = Reserva Biológica do Una (Brasil), La Selva = La Selva Biological Station $($ Costa Rica), BCI = Ilha de Barro Colorado (Panamá), Cocha Cashu = Cocha Cashu Biological Station (Perú). Tipos florestais: FOD = Floresta Ombrófila Densa, FES = Floresta Estacional Semidecidual.

Table 1. Total number of species and families in different neotropical forests. Localities: PECB = Carlos Botelho State Park (Brazil), REMC = Macaé de Cima Ecological Reserve (Brazil), Una = Una Biological Reserve (Brazil), La Selva = La Selva Biological Station (Costa Rica), BCI = Barro Colorado Island (Panama), Cocha Cashu $=$ Cocha Cashu Biological Station $($ Peru $)$. Forest types: FOD $=$ Tropical rain forest, FES $=$ Tropical seasonal forest.

\begin{tabular}{lcccccc}
\hline & PECB & REMC & Una & La Selva & BCI & Cocha Cashu \\
\hline Área (ha) & 37.000 & 7.200 & 9.000 & 1.500 & 15.000 & 1.000 \\
Tipo florestal & FOD & FOD & FOD & FOD & FES & FOD \\
Espécies* & 1.154 & 1.103 & 1.038 & 1.450 & 966 & 1.215 \\
Famílias** $_{\text {Citação }}$ & 140 & 122 & 127 & 121 & 118 & 119 \\
\end{tabular}

*Para La Selva, BCI e Cocha Cashu o número total de espécies corrigido para incluir apenas espécies florestais.**Comparações do total de famílias devem considerar que os demais trabalhos não usaram o sistema APG III. 

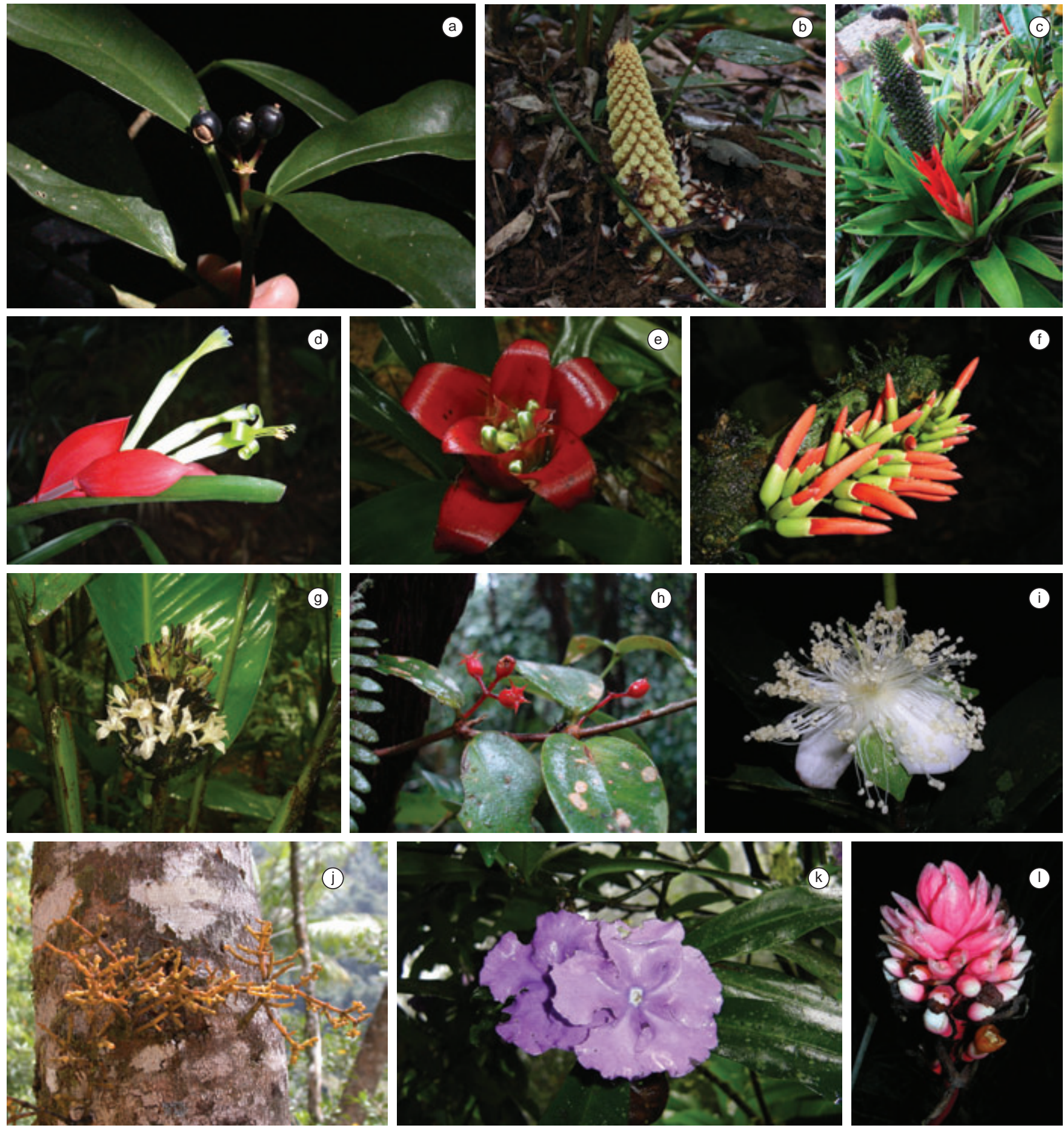

Figura 2. Algumas espécies ocorrentes no interior do Parque Estadual Carlos Botelho. a) Dendropanax australis (Araliaceae). b) Lophophytum leandrii (Balanophoraceae). c) Aechmea ornata (Bromeliaceae). d) Billbergia amoena (Bromeliaceae). e) Nidularium amazonicum (Bromeliaceae). f) Dahlstedtia pinnata (Fabaceae). g) Calathea monophylla (Marantaceae). h) Pleiochiton blepharodes (Melastomataceae). i) Eugenia bocainensis (Myrtaceae). j) Phoradendron fragile (Santalaceae). k) Brunfelsia pauciflora (Solanaceae). 1) Renealmia petasites (Zingiberaceae). Fotos: a,d-e,g,l) R.A.F. Lima. b-c,h,j) T.B. Breier. f,i,k-1) Débora C. Rother.

Figure 2. Some of the species occurring in the Carlos Botelho State Park. a) Dendropanax australis (Araliaceae). b) Lophophytum leandrii (Balanophoraceae). c) Aechmea ornata (Bromeliaceae). d) Billbergia amoena (Bromeliaceae). e) Nidularium amazonicum (Bromeliaceae). f) Dahlstedtia pinnata (Fabaceae). g) Calathea monophylla (Marantaceae). h) Pleiochiton blepharodes (Melastomataceae). i) Eugenia bocainensis (Myrtaceae). j) Phoradendron fragile (Santalaceae). k) Brunfelsia pauciflora (Solanaceae). 1) Renealmia petasites (Zingiberaceae). Photos: a,d-e,g,l) R.A.F. Lima. b-c,h,j) T.B. Breier. f,i,k-l) Débora C. Rother. 
Entre as famílias mais ricas encontradas no PECB vale destacar Myrtaceae (85 spp.), Orchidaceae (81 spp.), Fabaceae (57 spp.), Asteraceae (54 spp.), Melastomataceae (54 spp.), Lauraceae (53 spp.), Rubiaceae (51 spp.) e Bromeliaceae (43 spp.). Juntas estas famílias somaram 478 espécies, ou seja, $42 \%$ da flora do PECB (Figura 3). Estas famílias estiveram, de maneira geral, entre as mais ricas em outras unidades de conservação na Floresta Atlântica do Sudeste do Brasil (Barros et al. 1991, Lima \& Guedes-Bruni 1997, Mamede et al. 2001, Kirizawa et al. 2007). Apenas uma espécie de gimnosperma foi encontrada (Podocarpus sellowii-Podocarpaceae), visto que os indivíduos de Araucaria angustifolia (Araucariaceae) foram introduzidos (não há registros da espécie ocorrendo naturalmente nas florestas do parque). As pteridófítas apresentaram 123 espécies distribuídas em 55 gêneros e 21 famílias, um valor relativamente alto apesar do pequeno esforço de coleta direcionado para este grupo no PECB. Assim, é possível (e provável) que muitas espécies ainda sejam encontradas nos domínios do Parque. Os gêneros mais ricos no PECB foram Eugenia (34 spp.), Ocotea (26 spp.), Leandra, Myrcia, Vriesea (18 spp. cada), Piper, Solanum (16S spp.) e Miconia (14 spp.) que abrigaram $14 \%$ das espécies do parque. A alta riqueza destes gêneros foi similar ao encontrado por Lima \& Guedes-Bruni (1997) e Amorim et al. (2009) nas florestas montanas do Rio de Janeiro e Bahia, respectivamente.

Quanto à distribuição espacial dos registros, foram listadas 704 espécies para o município de São Miguel Arcanjo, 867 para Sete Barras e 144 para Capão Bonito. Nenhum registro foi encontrado para o município de Tapiraí. Em geral, espécies de ocorrência em áreas mais elevadas, como Achyrocline alata (Asteraceae), Acianthera auriculata (Orchidaceae), Aiouea acarodomatifera (Lauraceae), Blechnum cordatum (Blechnaceae), Canistrum cyathiforme (Bromeliaceae), Chusquea spp. (Poaceae),
Drimys brasiliensis (Winteraceae), Fuchsia regia (Onagraceae), Gordonia fruticosa (Theaceae), Hymenophyllum caudiculatum (Hymenophyllaceae), Ilex paraguariensis, I. taubertiana (Aquifoliaceae), Mollinedia argyrogyna (Monimiaceae), Nematanthus strigillosus (Gesneriaceae), Nidularium rutilans (Bromeliaceae), Quiina magallano-gomesii (Ochnaceae), Schefflera angustissima (Araliaceae), Ternstroemia brasiliensis (Pentaphyllacaceae) e Weinmannia spp. (Cunoniaceae), foram registradas para os municípios de São Miguel Arcanjo e Capão Bonito que concentram os trechos mais altos do Parque. Por outro lado, espécies típicas de florestas de terras baixas estiveram mais restritas ao município de Sete Barras, que apesar de atingir áreas elevadas do Parque, abriga a maior parte das Florestas Submontanas e os pequenos trechos de Florestas de Terras Baixas do PECB. Dentre os exemplos que ocorreram apenas neste município estão: Brosimum glazioui (Moraceae), Eriotheca pentaphylla (Malvaceae), Geonoma elegans (Arecaceae), Lindsaea arcuata (Lindsaeaceae), Pourouma guianensis (Urticaceae), Pradosia lactescens (Sapotaceae), Psychotria nuda (Rubiaceae), Rhipsalis grandiflora (Cactaceae), Sabicea villosa (Rubiaceae), Virola gardneri (Myristicaceae) e Vriesea rodigasiana (Bromeliaceae).

É importante destacar que, apesar da presente lista de espécies representar uma boa amostra da flora do PECB, algumas formas de vida e, consequentemente, algumas famílias foram pouco estudadas no Parque. Isto porque, dos 14 trabalhos encontrados para o Parque, apenas cinco não trataram exclusivamente de árvores (e.g. Philips \& Miller 2002, Breier 2005, Lima \& Moura 2006). Assim, acreditamos que futuros levantamentos acrescentarão poucas espécies arbóreas à lista apresentada aqui. Para ervas, epífitos e lianas, contudo, há uma carência de estudos e levantamentos direcionados que possam caracterizar de maneira apropriada a flora destas formas de vida

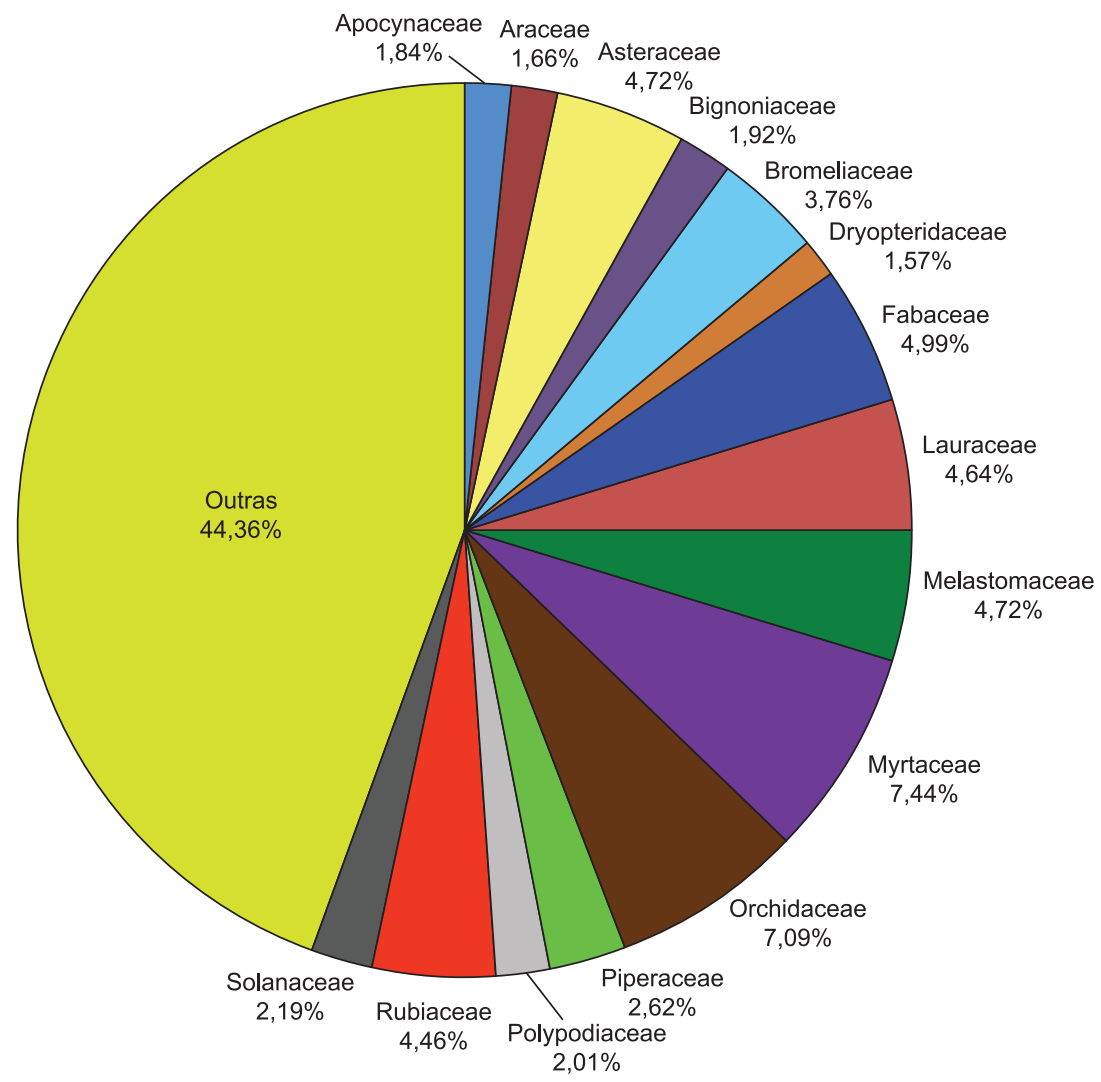

Figura 3. Famílias mais ricas do Parque Estadual Carlos Botelho e suas respectivas contribuições para a riqueza de total de espécies do Parque.

Figure 3. The most species-rich families in the Carlos Botelho state park and their respective contributions to the Park total species richness. 
no PECB. Famílias com grande número de espécies epifíticas e herbáceas, como Orchidaceae, Gesneriaceae, Bromeliaceae e Araceae, provavelmente são mais ricas do que o apresentado aqui. Estas famílias geralmente possuem alto grau de espécies endêmicas e/ou ameaçadas de extinção, reforçando ainda mais a necessidade de novos inventários para melhor caracterizar a flora do Parque.

Futuras coletas devem ser direcionadas para as áreas raras e pouco estudadas do PECB, como os campos de altitude, os trechos de Floresta Ombrófila Densa Alto-montana e de Terras Baixas, além das áreas de vegetação secundária. Áreas florestais nos municípios de Tapiraí e Capão Bonito também devem receber atenção especial, pois podem ter influência de elementos florísticos de formações florestais sazonais. Quanto às formas de vida, ervas devem ser estudadas por toda a unidade, enquanto levantamentos de lianas e epífitos devem ser direcionados para trechos de Floresta Ombrófila Densa Montana e Alto-Montana. Até onde sabemos, as pteridófitas foram amostradas apenas por Breier (2005), que levantou apenas epífitos vasculares e por levantamentos pontuais no interior da unidade. Assim, levantamentos de pteridófitas no PECB são igualmente necessários.

Do total de espécies registradas, 63 possuem algum grau de ameaça internacional, nacional ou estadual (Tabela 2). As famílias com maior número de espécies entre as ameaçadas foram
Myrtaceae (16), Lauraceae (10) e Gesneriaceae (7). A grande maioria delas foi citada como vulnerável. Contudo, dentre estas espécies estão espécies provavelmente extintas no Estado de São Paulo (Mollinedia oligotricha-Monimiaceae, Ilex taubertianaAquifoliaceae, e Nematanthus strigillosus-Gesneriaceae), espécies em risco crítico (Plinia complanata-Myrtaceae, Vriesea hieroglyphicaBromeliaceae, e Wilbrandia hibiscoides-Cucurbitaceae) e várias espécies ameaçadas. Dentre as ameaçadas, vale destacar aquelas ameaçadas no Estado de São Paulo: Borreria remota (Rubiaceae), Aiouea saligna, Beilschmiedia emarginata, Ocotea odorifera, Persea venosa, Rhodostemonodaphne macrocalyx (Lauraceae) e Handroanthus botelhensis (Bignoniaceae). A ameaça de boa parte das espécies está relacionada à redução da cobertura florestal e/ou à degradação dos fragmentos remanescentes (International... 2002, Mamede et al. 2007). Duas das três espécies citadas como praticamente extintas no Estado (Ilex taubertiana e Nematanthus strigillosus) são típicas de florestas acima de $1.000 \mathrm{~m}$ de altitude, um tipo de hábitat raro no Estado. Portanto, a ocorrência de tais espécies, aliada à alta riqueza de espécies encontrada, faz com que o PECB seja uma das áreas de floresta Atlântica com maior importância para a conservação da flora vascular brasileira e mundial.

Tabela 2. Espécies ameaçadas encontradas no Parque Estadual Carlos Botelho. Os cabeçalhos 'Mundo', 'Brasil' e 'SP' se referem às informações obtidas nas listas de espécies ameaçadas da International Union for Conservation of Nature, Fundação Biodiversitas e Secretaria do Meio Ambiente do Estado de São Paulo, respectivamente.

Table 2. Threatened species found in the Carlos Botelho State Park. Headers 'Mundo', 'Brasil' and 'SP' refer to the information collected from the International Union for Conservation of Nature, Fundação Biodiversitas and Secretaria do Meio Ambiente do Estado de São Paulo threatened species lists, respectively.

\begin{tabular}{|c|c|c|c|c|}
\hline Família & Espécie & Mundo & Brasil & SP \\
\hline Aquifoliaceae & Ilex taubertiana & - & - & EW \\
\hline Araceae & Anthurium langsdorffii & - & VU & - \\
\hline Bignoniaceae & Handroanthus botelhensis & - & EN & - \\
\hline Bromeliaceae & Aechmea gracilis & - & VU & - \\
\hline Bromeliaceae & Billbergia pyramidalis & - & - & VU \\
\hline Bromeliaceae & Vriesea hieroglyphica & - & $\mathrm{CR}$ & - \\
\hline Burmanniaceae & Dictyostega orobanchoides & - & - & VU \\
\hline Burseraceae & Protium widgrenii & - & - & VU \\
\hline Cactaceae & Rhipsalis pilocarpa & VU & - & - \\
\hline Combretaceae & Buchenavia hoehneana & VU & - & - \\
\hline Cucurbitaceae & Wilbrandia hibiscoides & - & - & CR \\
\hline Fabaceae & Inga lenticellata & VU & - & - \\
\hline Fabaceae & Inga praegnans & VU & - & - \\
\hline Fabaceae & Inga sellowiana & EN & - & - \\
\hline Fabaceae & Machaerium nyctitans & EN & - & - \\
\hline Gesneriaceae & Codonanthe devosiana & - & - & VU \\
\hline Gesneriaceae & Codonanthe gracilis & - & - & $\mathrm{VU}$ \\
\hline Gesneriaceae & Napeanthus primulifolius & - & - & $\mathrm{VU}$ \\
\hline Gesneriaceae & Nematanthus striatus & - & - & $\mathrm{VU}$ \\
\hline Gesneriaceae & Nematanthus strigillosus & - & - & EW \\
\hline Gesneriaceae & Nematanthus wettsteinii & - & - & $\mathrm{VU}$ \\
\hline Gesneriaceae & Sinningia douglasii & - & - & VU \\
\hline Lauraceae & Aiouea saligna & - & - & EN \\
\hline Lauraceae & Beilschmiedia emarginata & - & - & EN \\
\hline Lauraceae & Nectandra debilis & $\mathrm{CR}$ & DD & EN \\
\hline Lauraceae & Ocotea catharinensis & VU & VU & VU \\
\hline Lauraceae & Ocotea cf. bragai & - & VU & - \\
\hline
\end{tabular}

As categorias de ameaça são: EW: Extinto na natureza; CR: Risco crítico; EN: Ameaçada; e VU = Vulnerável.

Threatened species categories are: EW: Extinct in the wild; CR: Critical risk; EN: Endangered; and VU = Vulnerable. 
Lima, R.A.F. et al.

Tabela 2. Continuação...

\begin{tabular}{|c|c|c|c|c|}
\hline Família & Espécie & Mundo & Brasil & SP \\
\hline Lauraceae & Ocotea odorifera & VU & VU & EN \\
\hline Lauraceae & Ocotea porosa & VU & VU & EN \\
\hline Lauraceae & Ocotea tabacifolia & - & - & VU \\
\hline Lauraceae & Persea venosa & - & - & EN \\
\hline Lauraceae & Rhodostemonodaphne macrocalyx & - & - & $\mathrm{EN}$ \\
\hline Meliaceae & Cedrela fissilis & EN & - & - \\
\hline Meliaceae & Cedrela odorata & VU & - & - \\
\hline Meliaceae & Trichilia lepidota & VU & - & VU \\
\hline Monimiaceae & Mollinedia boracensis & - & VU & - \\
\hline Monimiaceae & Mollinedia gilgiana & $\mathrm{CR}$ & VU & - \\
\hline Monimiaceae & Mollinedia oligotricha & - & - & EW \\
\hline Monimiaceae & Mollinedia pachysandra & - & - & VU \\
\hline Moraceae & Brosimum glazioui & EN & - & VU \\
\hline Myrtaceae & Campomanesia phaea & VU & - & - \\
\hline \multirow[t]{2}{*}{ Myrtaceae } & Campomanesia schlechtendaliana & VU & - & - \\
\hline & Eugenia bocainensis & - & - & VU \\
\hline Myrtaceae & Eugenia brevistyla & EN & - & - \\
\hline Myrtaceae & Eugenia bunchosifolia & - & - & VU \\
\hline Myrtaceae & Eugenia burkartiana & - & - & VU \\
\hline Myrtaceae & Eugenia copacabanensis & - & - & VU \\
\hline Myrtaceae & Eugenia prasina & VU & - & - \\
\hline Myrtaceae & Myrcia flagellaris & - & - & VU \\
\hline Myrtaceae & Marlierea suaveolens & - & - & VU \\
\hline Myrtaceae & Myrceugenia campestris & VU & - & - \\
\hline Myrtaceae & Myrceugenia kleinii & VU & - & VU \\
\hline Myrtaceae & Myrceugenia pilotantha & VU & - & - \\
\hline Myrtaceae & Myrceugenia venosa & - & - & $\mathrm{VU}$ \\
\hline Myrtaceae & Plinia complanata & - & $\mathrm{CR}$ & - \\
\hline Myrtaceae & Siphoneugena densiflora & VU & - & - \\
\hline Picramniaceae & Picramnia ramiflora & - & - & VU \\
\hline Proteaceae & Roupala brasiliensis & - & - & VU \\
\hline Proteaceae & Roupala sculpta & - & $\mathrm{DD}$ & VU \\
\hline Rubiaceae & Borreria remota & - & - & EN \\
\hline Sapotaceae & Pouteria bullata & VU & - & - \\
\hline Sapotaceae & Pouteria psammophila & EN & - & - \\
\hline Urticaceae & Pilea cf. rhizobola & - & - & EW \\
\hline
\end{tabular}

As categorias de ameaça são: EW: Extinto na natureza; CR: Risco crítico; EN: Ameaçada; e VU = Vulnerável.

Threatened species categories are: EW: Extinct in the wild; CR: Critical risk; EN: Endangered; and VU = Vulnerable.

\section{Agradecimentos}

Gostaríamos de agradecer à administração do PECB (Instituto Florestal de São Paulo) pelo apoio durante o período de coletas que culminou nesta lista de espécies. Também agradecemos os comentários e sugestões de Fiorella F. Mazine-Capelo, Geraldo A.D.C. Franco e Natália M. Ivanauskas, e as fotos gentilmente cedidas por Débora Cristina Rother.

\section{Referências Bibliográficas}

AGUIAR, O.T. 2003. Comparação entre os métodos de quadrantes e parcelas na caracterização da composição florística e fitossociológica de um trecho de floresta ombrófila densa no Parque Estadual "Carlos Botelho"-São Miguel Arcanjo, São Paulo. Dissertação de mestrado, Universidade de São Paulo, Piracicaba.

AMORIM, A.M., THOMAS, W.W., CARVALHO, A.M.V.\&JARDIM, J.G. 2008. Floristics of the Una Biological Reserve, Bahia, Brazil. Mem. New York Bot. Gard. 100:67-146.
AMORIM, A.M., JARDIM, J.G., LOPES, M.M.M., FIASCHI, P., BORGES, R.A.X., PERDIZ, R.O. \& THOMAS, W.W. 2009. Angiospermas em remanescentes de Floresta Montana no sul da Bahia, Brasil. Biota Neotrop. 9(3): http://www.biotaneotropica.org.br/v9n3/pt/abstract?inv entory+bn02909032009.

ANGIOSPERM PHYLOGENY GROUP - APG. 2009. An update of the angiosperm phylogeny group classification for the orders and families of flowering plants: APG III. Bot. J. Linn. Soc. 161:105-121. http://dx.doi. org/10.1111/j.1095-8339.2009.00996.x

BARROS, F., MELO, M.M.R.F., CHIEA, S.A.C., KIRIZAWA, M., WANDERLEY, M.G.L. \& JUNG-MENDAÇOLLI, S.L. 1991. Caracterização geral da vegetação e listagem das espécies ocorrentes. In Flora Fanerogâmica da Ilha do Cardoso (M.M.R.F Melo, F. Barros, M.G.L. Wanderley, M. Kirizawa, S.L. Jung-Mendaçolli \& S.A.C. Chiea, eds.). Instituto de Botânica, São Paulo, v.1.

BREIER, T.B. 2005. O epifitismo vascular em florestas do Sudeste do Brasil. Tese de doutorado, Universidade Estadual de Campinas, Campinas.

CENTRO DE REFERÊNCIA EM INFORMAÇÃO AMBIENTAL CRIA. 2008. http://splink.cria.org.br. (ultimo acesso em 10/08/2008). 
CUSTÓDIO-FILHO, A.A., NEGREIROS, O.C., DIAS, A.C. \& FRANCO, G.A.D.C. 1992. Composição florística do estrato arbóreo do Parque Estadual de Carlos Botelho, SP. Rev. Inst. Flor. 4(1):184-198.

DIAS, A.C. 2005. Composição florística, fitossociologia, diversidade de espécies arbóreas e comparação de métodos de amostragem na Floresta Ombrófila Densa do Parque Estadual Carlos Botelho/SP-Brasil. Tese de doutorado, Universidade de São Paulo, Piracicaba.

DIAS, A.C., CUSTÓDIO-FILHO, A.A. \& FRANCO, G.A.D.C. 2000 Diversidade do componente arbóreo em Floresta Pluvial Atlântica secundária, São Paulo, Brasil. Rev. Inst. Flor.12(2):127-153.

FUNDAÇÃO BIODIVERSITAS. 2005. Revisão da Lista da Flora Brasileira Ameaçada de Extinção. http://www.biodiversitas.org.br (ultimo acesso em 12/12/2008).

GENTRY, A.H. 1990.Floristic similarities and differences between Southern Central America and Upper and Central Amazonia. In Four Neotropical Forests (A.H. Gentry, ed.). Yale University Press, New Haven, p.141-159.

GENTRY, A.H. \& DODSON, C.H. 1987. Diversity and biogeography of neotropical vascular epiphytes. Ann. Mo. Bot. Gard. 74(2):205-233. http://dx.doi.org/10.2307/2399395

HEINSDIJK, D. \& CAMPOS, J.C.C. 1967.Programa de manejo das florestas de produção estaduais. Silvic. São Paulo 6:365-405.

HOLMGREN, P.K., HOLMGREN, N.H. \& BARNETT, L.C. 1990. Index herbariorum. Part 1.The Herbaria of the World. 8nded. New York Botanical Garden/International Association for Plant Taxonomy, New York.

INSTITUTO BRASILEIRO DE GEOGRAFIA E ESTATÍSTICA IBGE. 1992. Manual técnico da vegetação brasileira. Instituto Brasileiro de Geografia e Estatística, Rio de Janeiro.

INTERNATIONAL PLANT NAMES INDEX -IPNI. 2008. Plant Name Query. http://www.ipni.org/ipni/plantnamesearchpage.do. (ultimoacessoem 21/11/2008).

INTERNATIONAL UNION FOR CONSERVATION OF NATURE IUCN. 2002. The IUCN Red List of Threatened Species. http://www. redlist.org. (ultimo acesso em 17/08/2003).

KIRIZAWA, M., SUGIYAMA, M., LOPES, E.A. \& CUSTODIO-FILHO, A. 2007. Flora da Reserva Biológica do Alto da Serra de Paranapiacaba, Santo André, São Paulo, Brasil. Instituto de Botanica, São Paulo. http:// www.ibot.sp.gov.br/PESQUISA/paranapiacaba/paranapiacaba.htm. (ultimo acesso em 10/08/2007).

LIMA, H.C. \& GUEDES-BRUNI, R.R. 1997. Diversidade de plantas vasculares na Reserva Ecológica de Macaé de Cima. In Serra de Macaé de Cima: diversidade florística e conservação em Mata Atlântica (H.C. Lima \& R.R. Guedes-Bruni, eds.). Jardim Botânico do Rio de Janeiro, Rio de Janeiro, p.29-39.

LIMA, R.A.F. \& MOURA, L.C. 2006. Canopy gap colonization in the Atlantic Montane Rain Forest. Braz. Arch. Biol. Tech. 49(6):953-965. http://dx.doi. org/10.1590/S1516-89132006000700013

MAMEDE, M.C.H., CORDEIRO, I. \& ROSSI, L. 2001. Flora vascular da Serra da Juréia, município de Iguape, São Paulo, Brasil. Bol. Inst. Bot. 15:63-124.

MAMEDE, M.C.H., SOUZA, V.C., PRADO, J., BARROS, F., WANDERLEY, M.G.L. \& RANDO, J.G. 2007. Livro vermelho das espécies vegetais ameaçadas de extinção no Estado de São Paulo. Instituto de Botânica, São Paulo.

MARTINI, A.M.Z., FIASCHI, P., AMORIM, A.M. \& PAIXÃO, J.L. 2007. A hot-point within a hot-spot: a high diversity site in Brazil's Atlantic Forest. Biodiver. Conserv. 16:3111-3128. http://dx.doi.org/10.1007/ s10531-007-9166-6

MELHEM, T.S., WANDERLEY, M.G.L., MARTINS, S.E., JUNGMENDAÇOLLI, S.L., SHEPHERD, G.J. \& KIRIZAWA, M. 2007. Flora Fanerogâmica do Estado de São Paulo. FAPESP, São Paulo,v.5.

MORAES, P.L.R. 1992. Espécies utilizadas na alimentação do mono-carvoeiro (Brachytelesarachnoides E. Geoffroy, 1806) no Parque Estadual de Carlos Botelho. Rev. Inst. Flor. 4(4):1206-1208.

MORAES, P.L.R. 2007. Taxonomy of Cryptocarya species of Brazil. Abc Taxa 3:1-191.
MORAN, R.C. 1995. Clave para las famílias de Pteridófitas. In Flora Mesoamericana (V. 1): Psilotaceae a Salvinaceae. (G. Davidse, M.S. Souza, \& S. Knapp, eds.). Universidad Nacional Autónoma de México, México, p.1-2.

MORELLATO, L.P.C. \& HADDAD, C.F.B. 2000. Introduction: the Brazilian Atlantic Forest. Biotropica 32(4b):786-792. http://dx.doi org/10.1111/j.1744-7429.2000.tb00618.x

MYERS, N., MITTERMEIER, R.A., MITTERMEIER, C.G., FONSECA, G.A.B. \& KENT, J. 2000. Biodiversity hotspots for conservation priorities. Nature 403(6772):853-858. http://dx.doi.org/10.1038/35002501

NEGREIROS, O.C., CUSTÓDIO-FILHO, A., DIAS, A.C., FRANCO, G.A.D.C., COUTO, H.T.Z., VIEIRA, M.G.L., \& MOURA-NETTO, B.V. 1995. Análise estrutural de um trecho de floresta pluvial tropical, Parque Estadual de Carlos Botelho, Núcleo Sete Barras (SP - Brasil). Rev. Inst. Flor. 7(1):1-33.

NONATO, F.R. \& WINDISCH, P.G. 2004. Vittariaceae (Pteridophyta) do Sudeste do Brasil. Rev. Bras. Bot. 27(1):149-161. http://dx.doi. org/10.1590/S0100-84042004000100016

OLIVEIRA-FILHO, A.T. \& FONTES, M.A.L. 2000. Patterns of floristic differentiation among Atlantic Forests in southeastern Brazil and the influence of climate.Biotropica 32(4b):793-810. http://dx.doi org/10.1111/j.1744-7429.2000.tb00619.x

PHILIPS, O. \& MILLER, J.S. 2002. Global Patterns of Plant Diversity: Alwyn H. Gentry's Forest Transect Data Set (Monographs in Systematic Botany from the Missouri Botanical Garden). Missouri Botanical Garden Press, St. Louis.

RIBEIRO, M.C., METZGER, J.P., MARTENSEN, A.C., PONZONI, F.J. \& HIROTA, M.M. 2009. The Brazilian Atlantic Forest: How much is left, and how is the remaining forest distributed? Implications for conservation. Biol. Conserv. 142:1141-1153. http://dx.doi.org/10.1016/j. biocon.2009.02.021

RODRIGUES, R.R. 2005. Parcelas Permanentes em 40 ha de florestas do Estado de São Paulo: uma experiência multidisciplinar. Universidade de São Paulo, Piracicaba. http://www.lerf.esalq.usp.br/parrel2005.php (último acesso em 15/11/2007).

ROYAL BOTANIC GARDENS, KEW. 2008. World Checklist of Selected Plant Families. http://www.kew.org/wcsp/ (último acesso em 11/11/2008).

SÃO PAULO (Estado). Secretaria do Meio Ambiente do Estado de São Paulo - SMA. 2006. Parque Estadual da Serra do Mar: Plano de Manejo. http:// www.iflorestal.sp.gov.br/Plano_de_manejo/PE_SERRA_MAR/index.asp (último acesso em 10/12/2008).

SMITH, A.R., PRYER, K.M., SCHUETTPELZ, E., KORALL, P., SCHNEIDER, H. \& WOLF, P.G. 2006. A classification for extant ferns. Taxon 55(3):705-731. http://dx.doi.org/10.2307/25065646

SHEPHERD, G.J. 2000. Conhecimento e diversidade de plantas terrestres do Brasil. Secretaria de Biodiversidade e Florestas, Ministério do Meio Ambiente, Brasília.

TROPICOS. 2009. http://www.tropicos.org. (último acesso em 11/11/2009).

UDULUTSCH, R.G. 2004. Composição florística da comunidade de lianas lenhosas em duas formações florestais do Estado de São Paulo. Dissertação de mestrado, Universidade de São Paulo, Piracicaba.

VIANA, V.M. \& TABANEZ, A.A.J. 1996. Biology and conservation of forest fragments in the Brazilian Atlantic Moist Forest. In Forest patches in tropical landscapes (J. Schelhas\&R. Greenberg, eds.). Island Press, Washington, p.151-167.

WANDERLEY, M.G.L., SHEPHERD, G.J., GIULIETTI, A.M., MELHEM, T.S., BITTRICH, V. \& KAMEYAMA, C. 2002. Flora Fanerogâmica do Estado de São Paulo. HUCITEC, São Paulo,v.2.

WANDERLEY, M.G.L., SHEPHERD, G.J., MELHEM, T.S., GIULIETTI, A.M. \& KIRIZAWA, M. 2003. Flora Fanerogâmica do Estado de São Paulo. FAPESP/RiMa, São Paulo, v.3.

WANDERLEY, M.G.L., SHEPHERD, G.J., MELHEM, T.S., MARTINS, S.E., KIRIZAWA, M. \& GIULIETTI, A.M. 2005. Flora Fanerogâmica do Estado de São Paulo. FAPESP/RiMa, São Paulo,v.4.

ZIPARRO, V.B., GUILHERME, F.A.G., ALMEIDA-SCABBIA, R.J. \& MORELLATO, L.P.C. 2005. Levantamento florístico de floresta atlântica no sul do Estado de São Paulo, Parque Estadual Intervales, Base Saibadela. Biota Neotrop. 5(1): http://www.biotaneotropica.org.br/v5n1/pt/abstract ?inventory+BN02605012005. 
Lima, R.A.F. et al.

\section{Apêndices}

Apêndice 1. Lista de espécies de plantas vasculares do Parque Estadual Carlos Botelho, atualizado até Janeiro de 2010. Registros de espécies em herbários são representados pelo código do herbário (sensu Holmgren et al. 1990), enquanto os números representam as fontes de informação onde as espécies são citadas. Legenda: Fonte de informação (Sc): 1= registros de campo; 2= Philips and Miller (2002); 3= Nonato and Windisch (2004); 4= Dias et al. (2000); 5= CustódioFilho et al. (1992); 6= Lima and Moura (2006); 7= Moraes (1992); 8= Negreiros et al. (1995); 9= Heinsdijk and Campos (1967). OTA, RAFL, TBB, VAOD e VCS correspondem aos números de coletor de Osny T. Aguiar, Renato A.F. Lima, Tiago B. Breier, Vinícius A.O. Dittrich e Vinícius C. Souza, respectivamente. Sinonímias são representadas por '=’, enquanto nomes erroneamente atribuídos a uma dada espécie são representados por ' '.

Appendix 1. List of the vascular plant species of the Carlos Botelho state park, updated to January 2010. Species records from herbaria are represented by the herbarium code (sensu Holmgren et al. 1990) while numbers represent the sources where the species were cited. Source (Sc): $1=$ field records; $2=$ Philips and Miller (2002); $3=$ Nonato and Windisch (2004); 4= Dias et al. (2000); 5= Custódio-Filho et al. (1992); 6= Lima and Moura (2006); 7= Moraes (1992); $8=$ Negreiros et al. (1995); 9= Heinsdijk and Campos (1967). OTA, RAFL, TBB, VAOD, and VCS correspond to the collector numbers of Osny T. Aguiar, Renato A.F. Lima, Tiago B. Breier, Vinícius A.O. Dittrich, and Vinícius C. Souza, respectively. Synonyms are represented by '=’, while names erroneously attributed to a given species are represented by ' $\sim$ '.

Família, espécie e autoria [sinonímia]

\section{Pteridófitas}

ANEMIACEAE

Anemia phyllitidis (L.) Sw.; Erva; Sc: SPSF

Anemia raddiana Link; Erva; Sc: SPSF

ASPLENIACEAE

Asplenium abscissum Willd.; Erva; Sc: BHCB/HRCB/MBM

Asplenium auriculatum Sw.; Erva/epífito; Sc: HRCB, TBB 697

Asplenium auritum Sw.; Epífito; Sc: TBB 698

Asplenium cirrhatum Rich. ex Willd. [= A. radicans var. cirrhatum (Rich. ex Willd.) Rosenst.]; Erva/epífito; Sc: BHCB/ $\mathrm{HRCB} / \mathrm{MBM} / \mathrm{SPSF}$

Asplenium inaequilaterale Willd.; Erva; Sc: SPSF

Asplenium kunzeanum Klotzsch ex Rosenst.; Erva; Sc: VAOD 1168

Asplenium mucronatum C. Presl; Epífito; Sc: ESA, TBB 452

Asplenium pteropus Kaulf.; Epífito; Sc: BHCB/HRCB, TBB 648

Asplenium raddianum Gaudich.; Erva; Sc: VAOD 1298

Asplenium scandicinum Kaulf.; Epífito; Sc: ESA/SPSF

Asplenium triquetrum N. Murak. \& R.C. Moran; Erva; Sc: BHCB/HRCB/MBM

BLECHNACEAE

Blechnum austrobrasilianum de la Sota; Erva; Sc: ESA

Blechnum binervatum subsp. acutum (Desv.) R.M. Tryon \& Stolze; Erva/epi; Sc: HRCB

Blechnum brasiliense Desv.; Erva; Sc: ESA/SPSF

Blechnum cordatum (Desv.) Hieron. [= B. regnellianum (Kunze) C.Chr.]; Erva; Sc: ESA/SPSF

Blechnum polypodioides Raddi; Erva; Sc: HRCB/SPSF

Blechnum serrulatum Rich.; Erva; Sc: HRCB

Salpichlaena volubilis (Kaulf.) J. Sm.; Liana; Sc: TBB 609

\section{CYATHEACEAE}

Alsophila setosa Kaulf. [= Nephelea setosa (Kaulf.) Tryon]; Arbusto; Sc: HRCB, 4, 5

Alsophila sternbergii (Sternb.) D.S. Conant [= Nephelea sternbergii (Pohl.) Tryon]; Arbusto; Sc: ESA, 2, 4, 5

Cyathea atrovirens (Langsd. \& Fisch.) Domin [= Alsophila atrovirens (Langsd. \& Fisch.) Pr.]; Arbusto; Sc: HRCB, 2, 4

Cyathea axillaris (Fée) Lellinger [ C. leucofolis Domin]; Arbusto; Sc: HRCB

Cyathea corcovadensis (Raddi) Domin [= Alsophila corcovadensis (Radd.) C.Chr.]; Arbusto; Sc: ESA/HRCB, 4, 5

Cyathea delgadii Sternb.; Arbusto; Sc: 2, 4, 5

Cyathea dichromatolepis (Fée) Domin [= Trichipteris dichromatolepis (Fée) Tryon]; Arbusto; Sc: HRCB, 2

Cyathea hirsuta C. Presl; Arbusto; Sc: HRCB 


\section{Família, espécie e autoria [sinonímia]}

Cyathea phalerata Mart. [= Trichipteris phalerata (Mart.) Barr.]; Arbusto; Sc: HRCB, 2 DENNSTAEDTIACEAE

Dennstaedtia dissecta (Sw.) T. Moore; Erva; Sc: HRCB

Pteridium arachnoideum (Kaulf.) Maxon; Erva; Sc: 1

DRYOPTERIDACEAE

Ctenitis pedicellata (H. Christ) Copel.; Erva; Sc: BHCB/HRCB

Didymochlaena truncatula (Sw.) J. Sm.; Erva; Sc: HRCB, 6

Elaphoglossum luridum (Fée) Christ [= E. crassinerve T. Moore]; Epífito; Sc: TBB 651

Elaphoglossum glabellum J.Sm.; Epífito; Sc: TBB 621

Elaphoglossum glaziovii (Fée) Brade; Epífito; Sc: HRCB/SPSF

Elaphoglossum herminieri (Bory ex Fée) T. Moore; Epífito; Sc: HRCB, TBB 516

Elaphoglossum iguapense Brade; Epífito; Sc: TBB 652

Elaphoglossum lingua (C. Presl) Brack.; Epífito; Sc: HRCB, TBB 506

Elaphoglossum nigrescens (Hook.) T. Moore ex Diels; Epífito; Sc: VAOD 1243

Elaphoglossum strictum (Raddi) T. Moore; Epífito; Sc: HRCB

Lastreopsis amplissima (C. Presl) Tindale; Erva; Sc: HRCB, 6

Lomagramma guianensis (Aubl.) Ching; Epífito; Sc: TBB 442

Megalastrum cf. connexum (Kaulf.) A.R. Sm. \& R.C. Moran; Erva; Sc: VAOD 1253

Olfersia cervina (L.) Kunze; Erva; Sc: HRCB, TBB 438

Polybotrya cylindrica Kaulf.; Epífito; Sc: HRCB, 2, 6, TBB 679

Rumohra adiantiformis (G.Forst.) Ching; Epífito; Sc: TBB 478

Stigmatopteris caudata (Raddi) C.Chr.; Erva/epífito; Sc: HRCB/MBM, TBB 447

Stigmatopteris heterocarpa (Fée) Rosenst.; Erva; Sc: BHCB/HRCB, 6

\section{GLEICHENIACEAE}

Dicranopteris flexuosa (Schrad.) Underw. [= Gleichenia flexuosa (Schrad.) Mett. ]; Erva; Sc: HRCB/SPSF

Gleichenella pectinata (Willd.) Ching; Erva; Sc: SPSF

Sticherus bifidus (Willd.) Ching [= Gleichenia pubescens H.B.K.]; Erva; Sc: SPSF

Sticherus lanuginosus (Fée) Nakai [= Gleichenia pennigera (Mart.) Moore; Sticherus penniger (Mart.) Copel.]; Erva; Sc: SPSF

Sticherus nigropaleaceus (Sturm) Prado; Erva; Sc: HRCB

\section{HYMENOPHYLLACEAE}

Abrodictyum rigidum (Sw.) Ebihara \& Dubuisson [= Trichomanes rigidum Sw.]; Erva; Sc: HRCB/SPSF

Didymoglossum cf. angustifrons Fée [= Trichomanes cf. angustifrons (Fée) Wess. Boer]; Epífito; Sc: VAOD 1158

Didymoglossum krausii (Hook. \& Grev.) C. Presl [= Trichomanes krausii Hook. \& Grev.]; Epífito; Sc: UEC

Didymoglossum reptans (Sw.) C. Presl [= Trichomanes reptans Sw.]; Epífito; Sc: UEC

Hymenophyllum asplenioides (Sw.) Sw.; Epífito; Sc: ESA/UEC

Hymenophyllum caudiculatum Mart.; Epífito; Sc: ESA/IAC/SPSF

Hymenophyllum elegans Spreng.; Epífito; Sc: BHCB/HRCB

Hymenophyllum fragile (Hedw.) C.V. Morton; Epífito; Sc: TBB 684

Hymenophyllum hirsutum (L.) Sw.; Epífito; Sc: HRCB, TBB 683

Hymenophyllum polyanthos (Sw.) Sw.; Epífito; Sc: TBB 686

Hymenophyllum pulchellum Schltdl. \& Cham.; Epífito; Sc: BHCB/HRCB, TBB 708

Polyphlebium angustatum (Carmich.) Ebihara \& Dubuisson [= Trichomanes angustatum Carmich.]; Epífito; Sc: BHCB/ HRCB/SPSF, TBB 147 
Lima, R.A.F. et al.

Apêndice 1. Continuação...

Família, espécie e autoria [sinonímia]

Polyphlebium diaphanum (Kunth) Ebihara \& Dubuisson [= Trichomanes diaphanum Kunth]; Epífito; Sc: UEC

Polyphlebium pyxidiferum (L.) Ebihara \& Dubuisson [= Trichomanes pyxidiferum L.]; Epífito; Sc: BHCB, TBB 433

Trichomanes cristatum Kaulf.; Epífito; Sc: TBB 1170

Trichomanes polypodioides L.; Epífito; Sc: HRCB/SPSF, TBB 693

Vandenboschia radicans (Sw.) Copel. [= Trichomanes radicans Sw.]; Liana; Sc: UEC/SPSF

LINDSAEACEAE

Lindsaea arcuata Kunze; Erva; Sc: HRCB

Lindsaea bifida (Kaulf.) Mett. ex. Kuhn; Erva; Sc: ESA

Lindsaea lancea (L.) Bedd. var. lancea; Erva; Sc: HRCB, TBB 1167

LOMARIOPSIDACEAE

Lomariopsis marginata (Schrad.) Kuhn; Epífito; Sc: TBB 483

Nephrolepis rivularis (Vahl) Mett. ex Krug; Epífito; Sc: TBB 1053

LYCOPODIACEAE

Huperzia flexibilis (Fée) B. Øllg.; Epífito; Sc: TBB 146

Huperzia heterocarpon (Fée) Holub; Epífito; Sc: SPSF

Huperzia mandiocana (Raddi) Trevis.; Epífito; Sc: TBB 527

Lycopodiella cernua (L.) Pic.-Serm.; Erva; Sc: SPSF

LYGODIACEAE

Lygodium volubile Sw.; Liana; Sc: SPSF

MARATTIACEAE

Eupodium kaulfussii (J. Sm.) J. Sm. [= Marattia laevis Sm.]; Erva; Sc: VAOD 1182

OPHIOGLOSSACEAE

Ophioglossum palmatum L. [= Cheiroglossa palmata (L.) C.Presl]; Epífito; Sc: 1

\section{POLYPODIACEAE}

Campyloneurum acrocarpon Fée; Epífito; Sc: BHCB/HRCB/MBM, TBB 567

Campyloneurum minus Fée; Epífito; Sc: BHCB/HRCB/MBM/SPSF, TBB 145

Campyloneurum nitidum (Kaulf.) C. Presl; Epífito; Sc: HRCB, TBB 659

Campyloneurum rigidum J.Sm.; Epífito; Sc: HRCB, TBB 513

Ceradenia spixiana (Mart. ex Mett.) L.E. Bishop; Epífito; Sc: HRCB, TBB 707

Cochlidium serrulatum (Sw.) L.E. Bishop; Epífito; Sc: BHCB/HRCB, TBB 524

Microgramma geminata (Schrad.) R.M. Tryon \& A.F. Tryon; Epífito; Sc: TBB 1051

Microgramma percussa (Cav.) de la Sota; Epífito; Sc: BHCB/HRCB/MBM, TBB 484

Microgramma tecta (Kaulf.) Alston; Epífito; Sc: TBB 425a

Microgramma vacciniifolia (Langsd. \& Fisch.) Copel.; Epífito; Sc: 425b

Micropolypodium achilleifolium (Kaulf.) Labiak \& F.B. Matos; Epífito; Sc: VAOD 1290

Pecluma chnoophora (Kunze) Salino \& F.C. Assis [= Polypodium chnoophorum Kunze]; Epífito; Sc: HRCB

Pecluma recurvata (Kaulf.) M.G. Price; Epífito; Sc: TBB 539

Pecluma truncorum (Lindm.) M.G. Price; Epífito; Sc: TBB 149

Pleopeltis astrolepis (Liebm.) E. Fourn.; Epífito; Sc: TBB 618b

Pleopeltis desvauxii (Klotzsch) Salino [ Dicranoglossum furcatum (L.) J.Sm.]; Epífito; Sc: TBB 509

Pleopeltis hirsutissima (Raddi) de la Sota [= Polypodium hirsutissimum Raddi]; Epífito; Sc: HRCB/SPSF, TBB 535

Pleopeltis pleopeltifolia (Raddi) Alston [ Pleopeltis angusta Willd.]; Epífito; Sc: TBB 504

Serpocaulon catharinae (Langsd. \& Fisch.) A.R. Sm. [= Polypodium catharinae Langsd. \& Fisch.]; Epífito; Sc: SPSF, TBB 531 
Apêndice 1. Continuação...

\begin{tabular}{|c|}
\hline Família, espécie e autoria [sinonímia] \\
\hline Serpocaulon fraxinifolium (Jacq.) A.R. Sm.; Erva/epífito; Sc: HRCB \\
\hline Serpocaulon meniscifolium (Langsd. \& Fisch.) A.R. Sm. [= Polypodium meniiscifolium Langsd. \& Fisch.]; Epífito; Sc: SPSF \\
\hline Terpsichore chrysleri (Copel.) A.R. Sm.; Epífito; Sc: ESA/SPSF \\
\hline Terpsichore reclinata (Brack.) Labiak; Epífito; Sc: HRCB \\
\hline PTERIDACEAE \\
\hline Hecistopteris pumila (Spreng.) J.Sm.; Epífito; Sc: BHCB/HRCB, TBB 687 \\
\hline Pityrogramma calomelanos (L.) Link; Erva; Sc: HRCB \\
\hline Polytaenium cajenense (Desv.) Benedict; Epífito; Sc: TBB 645 \\
\hline Pteris decurrens C. Presl; Erva; Sc: HRCB/SPSF \\
\hline Radiovittaria stipitata (Kunze) E.H. Crane; Epífito; Sc: TBB 507 \\
\hline Vittaria graminifolia Kaulf.; Epífito; Sc: UEC, 3 \\
\hline Vittaria lineata (L.) Sm.; Epífito; Sc: TBB 569 \\
\hline SACCOLOMATACEAE \\
\hline Saccoloma inaequale (Kunze) Mett.; Erva; Sc: HRCB \\
\hline SELAGINELLACEAE \\
\hline Selaginella contigua Baker; Erva/epífito; Sc: TBB 1165 \\
\hline Selaginella flexuosa Spring; Epífito; Sc: TBB 1166 \\
\hline Selaginella sulcata (Desv. ex Poir.) Spring ex Mart.; Erva; Sc: ESA \\
\hline TECTARIACEAE \\
\hline Tectaria incisa Cav.; Erva/epífito; Sc: HRCB, TBB 443 \\
\hline THELYPTERIDACEAE \\
\hline Thelypteris decussata var. brasiliensis (C. Chr.) A.R. Sm.; Erva; Sc: BHCB/HRCB \\
\hline $\begin{array}{l}\text { Thelypteris gymnosora Ponce [= T. ptarmica var. asplenioides (Kunze ex Mett.) C.F. Reed]; Epífito; Sc: BHCB/HRCB/ } \\
\text { MBM, TBB } 1164 \\
\text { Thelypteris opposita (Vahl) Ching; Erva; Sc: BHCB/HRCB }\end{array}$ \\
\hline Thelypteris raddii (Rosenst.) Ponce; Erva; Sc: HRCB \\
\hline WOODSIACEAE \\
\hline Diplazium cristatum (Desr.) Alston; Erva; Sc: HRCB/MBM \\
\hline
\end{tabular}

Diplazium cristatum (Desr.) Alston; Erva; Sc: HRCB/MBM

PODOCARPACEAE

Podocarpus sellowii Klotzsch; Árvore; Sc: OTA 1368

\section{Angiospermas - Monocotiledôneas}

ALSTROEMERIACEAE

Alstroemeria foliosa Mart. ex Schult. \& Schult.f.; Erva; Sc: UEC

Alstroemeria speciosa M. C. Assis; Erva; Sc: UEC

AMARYLLIDACEAE

Hippeastrum aulicum Herb.; Erva; Sc: ESA

Hippeastrum puniceum (Lam.) Kuntze; Erva; Sc: ESA

ARACEAE

Anthurium comtum Schott; Epífito; MO

Anthurium intermedium Kunth; Epífito; Sc: ESA

Anthurium langsdorffii Schott; Epífito; Sc: ESA, TBB 164

Anthurium pentaphyllum (Aubl.) G. Don; Epífito; Sc: ESA, TBB 590

Anthurium scandens (Aubl.) Engl.; Epífito; Sc: ESA, TBB 448

Anthurium sellowianum Kunth [= A. crassipes Engl.]; Epífito; Sc: ESA/SPSF/UEC 
Lima, R.A.F. et al.

Apêndice 1. Continuação...

Família, espécie e autoria [sinonímia]

Heteropsis rigidifolia Engl.; Epífito; Sc: UEC

Monstera adansonii Schott; Epífito; Sc: ESA/SPSF, TBB 511

Philodendron appendiculatum Nadruz \& Mayo; Epífito; Sc: ESA/SPSF

Philodendron corcovadense Kunth; Epífito; Sc: TBB 532

Philodendron crassinervium Lindl.; Epífito; Sc: TBB 510

Philodendron eximium Schott; Epífito; Sc: 1

Philodendron glaziovii Hook. f.; Epífito; Sc: ESA

Philodendron loefgrenii Engl.; Epífito; Sc: TBB 496

Philodendron martianum Engl.; Epífito; Sc: TBB 469

Philodendron obliquifolium Engl.; Epífito; Sc: ESA/SPSF, TBB 143

Philodendron ochrostemon Schott; Epífito; Sc: TBB 525

Philodendron vargealtense Sakur.; Epífito; Sc: TBB 1093

Syngonium vellozianum Schott; Epífito; Sc: TBB 514

ARECACEAE

Astrocaryum aculeatissimum (Schott) Burret; Árvore; Sc: 1

Attalea dubia (Mart.) Burret; Árvore; Sc: 1, 5

Bactris setosa Mart.; Arbusto; Sc: 6

Euterpe edulis Mart.; Árvore; Sc: 2, 4, 5, 6, 8

Geonoma elegans Mart.; Arbusto; Sc: ESA

Geonoma gamiova Barb. Rodr.; Arbusto; Sc: ESA, 6

Geonoma pauciflora Mart.; Arbusto; Sc: ESA

Geonoma schottiana Mart.; Arbusto; Sc: ESA, 6

Lytocaryum hoehnei (Burret) Toledo; Arbusto; Sc: 1

BROMELIACEAE

Aechmea coelestis (K. Koch) E. Morren; Epífito; Sc: TBB 151, 568

Aechmea cylindrata Lindm.; Epífito; Sc: RB/SP

Aechmea gamosepala Wittm.; Epífito; Sc: UEC/RB

Aechmea gracilis Lindm.; Epífito; Sc: SP

Aechmea nudicaulis (L.) Griseb.; Epífito; Sc: TBB 564

Aechmea organensis Wawra; Epífito; Sc: UEC/SP

Aechmea ornata Baker; Epífito; Sc: TBB 1076

Aechmea pectinata Baker; Epífito; Sc: TBB 477

Billbergia amoena (Lodd.) Lindl.; Epífito; Sc: ESA/SPSF, TBB 148

Billbergia distachia (Vell.) Mez; Epífito; Sc: RB

Billbergia pyramidalis (Sims) Lindl.; Epífito; Sc: ESA/SPSF

Canistropsis billbergioides (Schult. \& Schult. f.) Leme [= Nidularium billbergioides (Schult. \& Schult.f.) L.B. Sm.]; Epífito; Sc: ESA, TBB 579

Edmundoa lindenii (Regel) Leme [= Canistrum lindenii (Regel) Mez]; Epífito; Sc: ESA/UEC/RB/SP

Neoregelia laevis (Mez) L.B. Sm.; Epífito; Sc: SP, 1

Nidularium amazonicum (Baker) Linden \& E. Morren ex Lindm. [= N. krisgreeniae Leme]; Epífito; Sc: TBB 144

Nidularium campo-alegrense Leme; Epífito; Sc: RB

Nidularium innocentii Lem.; Epífito; Sc: ESA/SPSF

Nidularium rutilans E. Morren; Epífito; Sc: 1

Quesnelia violacea Wand. \& S.L. Proença; Epífito; Sc: RB 


\section{Família, espécie e autoria [sinonímia]}

Racinaea spiculosa (Griseb.) M.A. Spencer \& L.B. Sm. [=Tillandsia spiculosa Griseb]; Epífito; Sc: TBB 518

Tillandsia geminiflora Brongn.; Epífito; Sc: ESA

Tillandsia globosa Wawra; Epífito; Sc: UEC

Tillandsia stricta Sol.; Epífito; Sc: TBB 673

Tillandsia tenuifolia L.; Epífito; Sc: ESA, TBB 1055

Vriesea altodaserrae L.B. Sm.; Epífito; Sc: UEC

Vriesea atra Mez; Epífito; Sc: TBB 1074

Vriesea carinata Wawra; Epífito; Sc: ESA/SPSF/UEC

Vriesea drepanocarpa (Baker) Mez; Epífito; Sc: TBB 415

Vriesea ensiformis (Vell.) Beer; Epífito; Sc: ESA/SPSF, TBB 422

Vriesea erythrodactylon E. Morren ex Mez; Epífito; Sc: ESA

Vriesea flava A.F. Costa, H. Luther \& Wand.; Epífito; Sc: RB

Vriesea friburgensis var. paludosa (L. B. Sm.) L. B. Sm. [=V. paludosa L. B. Sm.]; Epífito; Sc: TBB 781, 799

Vriesea hieroglyphica (Carrière.) E.Morren; Epífito; Sc: TBB 558

Vriesea incurvata Gaudich.; Epífito; Sc: UEC/SPSF, TBB 696

Vriesea jonghei (Libon ex K. Koch) E. Morren [= V. gamba F. Mull.]; Epífito; Sc: ESA

Vriesea longiscapa Ule; Epífito; Sc: RB, TBB 444

Vriesea philippocoburgii Wawra; Epífito; Sc: TBB 1080

Vriesea rodigasiana E. Morren; Epífito; Sc: ESA/SPSF, TBB 474

Vriesea scalaris E. Morren; Epífito; Sc: 1

Vriesea taritubensis E. Pereira \& L.A. Penna; Epífito; Sc: UEC

Vriesea unilateralis (Baker) Mez; Epífito; Sc: ESA, TBB 1094

Vriesea vagans (L.B. Sm.) L.B. Sm.; Epífito; Sc: TBB 476

Wittrockia cyathiformis (Vell.) Leme [= Canistrum cyathiforme (Vell.) Mez]; Epífito; Sc: RB

BURMANNIACEAE

Dictyostega orobanchoides (Hook.) Miers; Erva; Sc: ESA/SPSF

\section{COMMELINACEAE}

Commelina obliqua Vahl; Erva; Sc: ESA/SPSF

Dichorisandra paranaensis D.Maia, Cervi \& Tardivo; Erva; Sc: ESA

Dichorisandra pubescens Mart. ex Schult. f.; Erva; Sc: ESA, 6

Dichorisandra villosula Mart. ex Schult. f.; Erva; Sc: ESA

Tripogandra diuretica (Mart.) Handlos; Erva; Sc: ESA

\section{COSTACEAE}

Costus spiralis (Jacq.) Roscoe; Erva; Sc: UEC, 6

\section{CYCLANTHACEAE}

Thoracocarpus bissectus (Vell.) Harling; Epífito/herb; Sc: TBB 672

\section{CYPERACEAE}

Becquerelia sp.; Erva; Sc: ESA

Cyperus luzulae (L.) Retz.; Erva; Sc: UEC/SPSF

Eleocharis montana (Kunth) Roem. \& Schult.; Erva; Sc: NY

Fimbristylis complanata (Retz.) Link; Erva; Sc: UEC

Fimbristylis dichotoma (L.) Vahl; Erva; Sc: UEC

Hypolytrum schraderianum Nees; Erva; Sc: ESA/UEC 
Lima, R.A.F. et al.

Apêndice 1. Continuação...

Família, espécie e autoria [sinonímia]

Lagenocarpus rigidus (Kunth) Nees; Erva; Sc: UEC

Pleurostachys distichophylla (Boeckeler) C.B.Clarke [ P. densifoliata H. Pfeiff.]; Erva; Sc: ESA/SPSF/UEC

Pleurostachys foliosa Kunth; Erva; Sc: MO

Pleurostachys gaudichaudii Brongn.; Erva; Sc: ESA/SPSF

Pleurostachys urvillei Brongn.; Erva; Sc: RAFL 524

Rhynchospora breviuscula $\mathrm{H}$. Pfeiff.; Erva; Sc: ESA/SPSF

Rhynchospora polyantha Steud.; Erva; Sc: ESA

Rhynchospora rugosa (Vahl) Gale; Erva; Sc: NY

Scleria latifolia Sw.; Erva; Sc: ESA/SPSF

Scleria panicoides Kunth; Erva; Sc: ESA

Scleria plusiophylla Steud.; Erva; Sc: SPSF

DIOSCOREACEAE

Dioscorea marginata Griseb.; Liana; Sc: ESA

Dioscorea subhastata Vell.; Liana; Sc: SPSF

HELICONIACEAE

Heliconia angusta Vell.; Erva; Sc: ESA

Heliconia farinosa Raddi [= H. velloziana L. Emygdio]; Erva; Sc: ESA

HYPOXIDACEAE

Hypoxis decumbens L.; Erva; Sc: ESA

IRIDACEAE

Neomarica cf. northiana (Scheneev.) Sprague; Erva; Sc: ESA

Sisyrinchium commutatum Klatt; Erva; Sc: ESA

Sisyrinchium micranthum Cav.; Erva; Sc: UEC

Trimezia martinicensis (Jacq.) Herb.; Erva; Sc: ESA/SPSF

JUNCACEAE

Juncus microcephalus Kunth; Erva; Sc: NY

MARANTACEAE

Calathea monophylla (Vell.) Körn. [= C. communis Wand. \& S.Vieira]; Erva; Sc: ESA/SPSF

Calathea prolifera (Vell.) J.M.A.Braga [= C. longifolia (Schauer) Klotzsch, C. macilenta Lindl.]; Erva; Sc: ESA

Ctenanthe lanceolata Petersen; Erva; Sc: ESA/SPSF

Stromanthe papillosa Petersen; Erva; Sc: INPA

Stromanthe thalia (Vell.) J.M.A.Braga; Erva; Sc: TBB 628

Stromanthe tonckat (Aubl.) Eichler; Erva; Sc: ESA/SPSF

\section{ORCHIDACEAE}

Acianthera auriculata (Lindl.) Pridgeon \& M.W.Chase [= Pleurothallis auriculata Lindl.]; Epífito; Sc: TBB 682

Acianthera saundersiana (Rchb. f.) Pridgeon \& M.W.Chase [= Pleurothallis saundersiana Rchb. f.]; Epífito; Sc: TBB 450

Acianthera serpentula (Barb. Rodr.) F. Barros [= Pleurothallis serpentula Barb. Rodr.]; Epífito; Sc: TBB 561

Anathallis obovata (Lindl.) Pridgeon \& M.W.Chase [= Pleurothallis obovata Lindl.]; Epífito; Sc: 1

Barbrodria miersii (Lindl.) Luer [= Barbosella miersii (Lindl.) Schltr.]; Epífito; Sc: ESA

Baskervilla paranaensis (Kraenzl.) Schltr.; Epífito; Sc: ESA/SPSF, TBB 1064

Bifrenaria harrisoniae (Hook.) Rchb. f.; Epífito; Sc: TBB 605

Campylocentrum linearifolium Schltr. ex Mansf.; Epífito; Sc: ESA

Cattleya forbesii Lindl.; Epífito; Sc: TBB 1085 
Família, espécie e autoria [sinonímia]

Christensonella neowiedii (Rchb.f.) S.Koehler; Epífito; Sc: UEC

Cirrhaea dependens Rchb. f.; Epífito; Sc: TBB 457

Cleistes libonii (Rchb. f.) Schltr.; Erva/epífito; Sc: TBB 1067

Cleistes macrantha (Barb. Rodr.) Schltr.; Erva; Sc: ESA/SPSF

Dichaea mosenii Cogn.; Epífito; Sc: TBB 488

Dichaea pendula (Aubl.) Cogn.; Epífito; Sc: TBB 519

Dichaea trulla Rchb. f.; Epífito; Sc: TBB 586

Dictyophyllaria dietschiana (Edwall) Garay [= Vanilla dietschiana Edwall]; Epífito; Sc: ESA

Elleanthus brasiliensis Rchb. f.; Epífito; Sc: ESA/SPSF, TBB 480

Encyclia patens Hook.; Epífito; Sc: ESA/SPSF

Epidendrum armeniacum Lindl.; Epífito; Sc: ESA, TBB 580

Epidendrum avicula Lindl. [= Lanium avicula (Lindl.) Benth.]; Epífito; Sc: TBB 153

Epidendrum latilabre Lindl.; Epífito; Sc: TBB 521

Epidendrum parahybunense Barb. Rodr.; Epífito; Sc: ESA/SPSF

Epidendrum paranaense Barb. Rodr.; Epífito; Sc: TBB 1073

Epidendrum proligerum Barb. Rodr.; Epífito; Sc: TBB 453

Epidendrum ramosum Jacq.; Epífito; Sc: TBB 152

Epidendrum rigidum Jacq.; Epífito; Sc: TBB 565

Epidendrum secundum Jacq. [= E. elongatum Jacq.]; Epífito; Sc: ESA/SPSF/UEC

Epidendrum strobiliferum Rchb. f.; Epífito; Sc: ESA

Eulophia alta (L.) Fawc. \& Rendle; Erva; Sc: ESA

Eurystyles actinosophila (Barb. Rodr.) Schltr.; Epífito; Sc: ESA

Gomesa recurva $\mathrm{R}$. Br.; Epífito; Sc: TBB 458

Gongora bufonia Lindl.; Epífito; Sc: TBB 460

Habenaria parviflora Lindl.; Erva; Sc: ESA

Heterotaxis brasiliensis (Brieger \& Illg) F. Barros [= Maxillaria brasiliensis Brieger \& Illg]; Epífito; Sc: TBB 159

Huntleya meleagris Lindl.; Epífito; Sc: TBB 1081

Isochilus linearis (Jacq.) R. Br.; Epífito; Sc: TBB 549

Lankesterella ceracifolia (Barb. Rodr.) Ames; Epífito; Sc: ESA, TBB 1103

Leptotes bicolor Lindl.; Epífito; Sc: TBB 1110

Maxillaria leucaimata Barb. Rodr.; Epífito; Sc: ESA

Maxillaria notylioglossa Rchb. f. [= M. cerifera Barb. Rodr.]; Epífito; Sc: ESA, TBB 598

Maxillaria ochroleuca Lodd. ex Lindl.; Epífito; Sc: ESA, TBB 503

Maxillaria parviflora (Poepp. \& Endl.) Garay; Epífito; Sc: TBB 587

Maxillaria picta Hook.; Epífito; Sc: 1

Maxillaria rigida Barb. Rodr.; Epífito; Sc: TBB 502

Octomeria diaphana Lindl.; Epífito; Sc: ESA/SPSF

Octomeria gracilis Barb. Rodr.; Epífito; Sc: TBB 602

Octomeria grandiflora Lindl.; Epífito; Sc: ESA

Octomeria juncifolia Barb. Rodr.; Epífito; Sc: TBB 156

Oeceoclades maculata (Lindl.) Lindl.; Epífito; Sc: ESA

Oncidium edwallii Cogn.; Epífito; Sc: ESA

Oncidium fimbriatum Lindl.; Epífito; Sc: 1 
Lima, R.A.F. et al.

Apêndice 1. Continuação...

Família, espécie e autoria [sinonímia]

Oncidium flexuosum Lodd.; Epífito; Sc: TBB 563

Oncidium hookeri Rolfe; Epífito; Sc: ESA

Ornithophora radicans (Rchb.f.) Garay \& Pabst; Epífito; Sc: TBB 520

Phymatidium falcifolium Lindl.; Epífito; Sc: TBB 610

Phymatidium hysteranthum Barb. Rodr.; Epífito; Sc: ESA

Pabstiella carinifera (Barb. Rodr.) Luer[= Pleurothallis carinifera (Barb. Rodr.) Cogn.]; Epífito; Sc: ESA

Pabstiella hypnicola (Lindl.) Luer [= Pleurothallis hypnicola Lindl.]; Epífito; Sc: TBB 596, 777

Pabstiella lineolata (Barb. Rodr.) Luer [= Pleurothallis lineolata (Barb. Rodr.) Cogn.]; Epífito; Sc: TBB 595

Pabstiella transparens (Schltr.) Luer [= Pleurothallis transparens Schltr.]; Epífito; Sc: ESA/SPSF

Polystachya estrellensis Rchb. f.; Epífito; Sc: ESA, TBB 464

Prescottia densiflora (Brongn.) Lindl.; Erva; Sc: UEC

Prescottia oligantha (Sw.) Lindl.; Erva; Sc: NY

Promenaea stapelioides (Link \& Otto) Lindl.; Epífito; Sc: TBB 512

Prosthechea fragans (Sw.) W.E. Higgins [= Encyclia fragans (Sw.) Lemée]; Epífito; Sc: TBB 574

Prosthechea glumacea (Lindl.) W.E.Higgins; Epífito; Sc: ESA/SPSF

Prosthechea vespa (Vell.) W.E. Higgins [= Encyclia vespa (Vell.) Dressler]; Epífito; Sc: TBB 154

Rodriguezia venusta Rchb. f.; Epífito; Sc: TBB 631

Rodrigueziopsis eleutherosepala (Barb. Rodr.) Schltr.; Epífito; Sc: ESA

Sacoila lanceolata (Aubl.) Garay [= Stenorrhynchos lanceolatum (Aubl.) Rich.]; Erva; Sc: UEC

Scaphyglottis emarginata (Garay) Dressler [= Reichenbachanthus emarginatus Garay]; Epífito; Sc: TBB 491

Scaphyglottis modesta (Rchb. f.) Schltr.; Epífito; Sc: TBB 490

Specklinia grobyi (Bateman ex Lindl.) F.Barros [= Pleurothallis marginalis Rchb. f., Pleurothallis grobyi Lindl.]; Epífito; Sc: ESA

Specklinia trifida (Lindl.) F. Barros [= Pleurothallis trifida Lindl.]; Epífito; Sc: TBB 530

Stelis calotricha Schltr.; Epífito; Sc: TBB 635

Stelis chasme Pridgeon \& M.W. Chase [= Pleurothallis hians Lindl.]; Epífito; Sc: ESA

Stelis deregularis Barb. Rodr. [= Pleurothallis deregularis (Barb. Rodr.) Luer]; Epífito; Sc: TBB 583

Trichosalpinx punctatifolia (Barb. Rodr.) Luer [= Pleurothallis punctatifolia (Barb. Rodr.) Pabst]; Epífito; Sc: ESA

Xylobium variegatum (Ruiz \& Pav.) Mansf.; Epífito; Sc: TBB 662

Zygopetalum maxillare Lodd.; Epífito; Sc: ESA/SPSF

POACEAE

Chusquea longispiculata L.G. Clark; Arbusto; Sc: MO

Chusquea meyeriana Rupr. ex Döll; Arbusto; Sc: SP

Chusquea oligophylla Rupr.; Arbusto; Sc: ESA/SPSF

Chusquea oxylepis (Hack.) Ekman; Arbusto; Sc: MO

Guadua tagoara (Nees) Kunth; Arbusto; Sc: SP, TBB 1066

Homolepis glutinosa (Sw.) Zuloaga \& Soderstr.; Erva; Sc: ESA

Homolepis villaricensis (Mez) Zuloaga \& Soderstr.; Erva; Sc: ESA

Merostachys multiramea Hack.; Arbusto; Sc: ESA/MO

Merostachys ternata Nees; Arbusto; Sc: MBM

Olyra glaberrima Raddi; Erva; Sc: ESA

Panicum pilosum Sw.; Erva; Sc: ESA/SPSF

Panicum polygonatum Schrad.; Erva; Sc: UEC

Paspalum regnellii Mez; Erva; Sc: SPSF 
Setaria sp.; Erva; Sc: ESA

SMILACACEAE

Smilax spicata Vell.; Liana; Sc: ESA

\section{XYRIDACEAE}

Xyris jupicai Rich.; Erva; Sc: ESA

\section{ZINGIBERACEAE}

Renealmia petasites Gagnep.; Erva; Sc: ESA

Angiospermas - angiospermas basais, magnoliídeas e eudicotiledôneas

ACANTHACEAE

Aphelandra ornata (Nees) T. Anderson; Erva; Sc: ESA/SPSF

Aphelandra schottiana (Nees) Profice [= Geissomeria schottiana Nees]; Erva; Sc: ESA

Hygrophila costata Nees [= H. latifolia Nees]; Erva; Sc: ESA/SPSF

Justicia carnea Lindl. [= Jacobinia carnea (Lindl.) Nicholson]; Erva; Sc: ESA

Justicia schenckiana Lindau; Erva; Sc: ESA

Mendoncia puberula Mart.; Liana; Sc: ESA

Mendoncia velloziana Mart.; Liana; Sc: ESA/HRCB

Ruellia sp.; Erva; Sc: UEC

Staurogyne mandioccana (Nees) Kuntze; Erva; Sc: ESA/SPSF

Stenandrium sp.; Erva; Sc: UEC

AMARANTHACEAE

Celosia grandifolia Moq.; Erva; Sc: ESA/SPSF

Cyathula prostrata Blume; Erva; Sc: ESA/SPSF

Iresine sp.; Liana; Sc: 2

Pfaffia pulverulenta (Mart.) Kuntze; Erva; Sc: UEC/SPSF

ANACARDIACEAE

Lithrea molleoides (Vell.) Engl.; Árvore; Sc: 1

Schinus terebinthifolius Raddi; Árvore; Sc: ESA

Tapirira guianensis Aubl.; Árvore; Sc: ESA/HRCB, 4, 5, 6, 7

\section{ANNONACEAE}

Annona dolabripetala Raddi; Árvore; Sc: UEC

Annona neosericea H.Rainer [= Rollinia sericea (R.E. Fr.) R.E. Fr.]; Árvore; Sc: ESA/SPSF, 4, 5, 6, 8

Annona parviflora (A. St.-Hil.) H. Rainer [= Rollinia parviflora A. St.-Hil.]; Árvore; Sc: SPSF, 6

Annona sylvatica A. St.-Hil. [= Rollinia sylvatica (A. St.-Hil.) Mart.]; Árvore; Sc: ESA/SPSF, 4

Duguetia lanceolata A. St.-Hil.; Árvore; Sc: ESA/UEC

Guatteria australis A. St.-Hil. [= G. nigrescens Mart.]; Árvore; Sc: ESA/HRCB/SPSF/UEC, 4, 5, 6, 8

Guatteria pohliana Schltdl.; Árvore; Sc: UEC

Xylopia brasiliensis Spreng.; Árvore; Sc: ESA

Xylopia langsdorfiana A. St.-Hil. \& Tul.; Árvore; Sc: 4, 6, OTA 1393

\section{APOCYNACEAE}

Aspidosperma olivaceum Müll. Arg.; Árvore; Sc: UEC, 6, 8

Aspidosperma tomentosum Mart. [= A. camporum Müll. Arg.]; Árvore; Sc: IAC

Ditassa burchellii var. vestita (Malme) Fontella; Liana; Sc: SPF

Forsteronia leptocarpa (Hook. \& Arn.) A. DC; Liana; Sc: ESA 
Lima, R.A.F. et al.

Apêndice 1. Continuação...

Família, espécie e autoria [sinonímia]

Forsteronia refracta Müll. Arg.; Liana; Sc: ESA/SPSF

Forsteronia rufa Müll. Arg.; Liana; Sc: UEC

Malouetia cestroides (Nees \& Mart.) Müll. Arg. [= M. arborea (Vell.) Miers.]; Árvore; Sc: ESA

Mandevilla funiformis (Vell.) K. Schum.; Liana; Sc: ESA/HRCB

Mandevilla urophylla (Hook. f.) Woodson; Liana; Sc: UEC

Matelea barrosiana Fontella; Liana; Sc: ESA

Matelea denticulata (Vahl.) Fontella \& E.A. Schwarz; Liana; Sc: SPF

Orthosia urceolata E. Fourn.; Liana; Sc: ESA/SPSF/SPF

Oxypetalum alpinum (Vell.) Fontella \& E.A. Schwarz; Liana; Sc: NY

Oxypetalum pedicellatum Decne.; Liana; Sc: UEC

Peltastes peltatus (Vell.) Woodson; Liana; Sc: ESA/SPSF

Peplonia axillaris (Vell.) Fontella \& Rapini [= Gonioanthela axillaris (Vell.) Fontella \& E.A. Schwarz.]; Liana; Sc: SPF

Rauvolfia sellowii Müll. Arg.; Árvore; Sc: HRCB

Rhabdadenia madida (Vell.) Miers [= R. pohlii Müll. Arg.]; Liana; Sc: UEC

Tabernaemontana catharinensis A. DC.; Arbusto; Sc: UEC/SPSF

Tabernaemontana hystrix Steud.; Árvore; Sc: ESA

Tabernaemontana laeta Mart.; Árvore; Sc: ESA

AQUIFOLIACEAE

Ilex dumosa Reissek [= I. amara (Vell.) Loes]; Arbusto; Sc: HRCB, 4, 5, 6

Ilex integerrima (Vell.) Reiss.; Arbusto; Sc: ESA

Ilex paraguariensis A. St.-Hil.; Árvore; Sc: IAC, 4, 5, 9

Ilex pseudobuxus Reissek; Árvore; Sc: ESA

Ilex taubertiana Loes.; Árvore; Sc: OTA 1377

ARALIACEAE

Dendropanax australis Fiaschi \& Jung-Mend.; Arbusto; Sc: RAFL 368

Oreopanax capitatus (Jacq.) Decne. \& Planch.; Árvore/hemi-epífito; Sc: ESA, TBB 577

Schefflera angustissima (Marchal) Frodin [= S. navarroi (A. Samp.) Frodin; Didymopanax angustissimus Marchal]; Árvore; Sc: ESA, 4, 5

ARISTOLOCHIACEAE

Aristolochia chamissonis (Klotzsch) Duch.; Liana; Sc: ESA

Aristolochia paulistana Hoehne; Liana; Sc: ESA

\section{ASTERACEAE}

Achyrocline alata (Kunth) DC.; Erva; Sc: ESA/SPSF

Adenostemma brasilianum (Pers.) Cass.; Erva; Sc: ESA/SPSF

Adenostemma involucratum R. M. King \& H. Rob.; Erva; Sc: NY

Aspilia foliacea (Spreng.) Baker; Erva; Sc: IAC

Austroeupatorium inulifolium (Kunth) R.M. King \& H. Rob. [= Eupatorium inulifolium Kunth]; Erva; Sc: ESA

Baccharis calvescens DC.; Arbusto; Sc: HRCB

Baccharis dentata (Vell.) G.M. Barroso; Arbusto; Sc: ESA

Baccharis dracunculifolia DC.; Arbusto; Sc: SPSF

Baccharis montana DC. [= B. elaeagnoides Steud. ex Baker]; Arbusto; Sc: ESA

Baccharis crispa Spreng. [= B. myriocephala DC.]; Arbusto; Sc: SPSF

Baccharis oreophila Malme; Arbusto; Sc: HRCB 
Flora do Parque Estadual Carlos Botelho

Apêndice 1. Continuação...

Família, espécie e autoria [sinonímia]

Baccharis reticularia DC.; Erva; Sc: SPSF

Baccharis singularis (Vell.) G.M. Barroso; Arbusto; Sc: ESA/SPSF

Barrosoa betonicaeformis (DC.) R.M. King \& H. Rob. [= Eupatorium betonicaeforme (DC.) Baker]; Erva; Sc: ESA/SPSF

Chaptalia nutans (L.) Pol.; Erva; Sc: ESA

Chromolaena laevigata (Lam.) R.M. King \& H. Rob. [= Eupatorium laevigatum Lam.]; Arbusto; Sc: SPSF

Chrysolaena platensis (Spreng.) H. Rob. [= Vernonia platensis (Spreng.) Less.]; Erva; Sc: ESA

Conyza bonariensis (L.) Cronquist; Erva; Sc: ESA

Critoniopsis quinqueflora (Less.) H. Rob. [= Vernonia quinqueflora Less.; Arbusto; Sc: ESA, 5

Cyrtocymura scorpioides (Lam.) H. Rob. [= Vernonia scorpioides (Lam.) Pers.; Erva; Sc: ESA/SPSF

Elephantopus mollis Kunth; Erva; Sc: ESA/SPSF

Eremanthus erythropappus (DC.) MacLeish [= Vanilosmopsis erythropappa (DC.) Sch. Bip.]; Árvore; Sc: ESA

Gochnatia polymorpha (Less.) Cabrera; Árvore; Sc: ESA/HRCB/SPSF

Heterocondylus alatus (Vell.) R.M. King \& H. Rob. [=H. vauthierianus (DC.) R.M. King \& H. Rob.; Eupatorium vauthierianum DC.]; Arbusto; Sc: SPSF/NY

Jaegeria hirta (Lag.) Less.; Erva; Sc: ESA/SPSF

Leptostelma maxima D. Don [= Erigeron maximus (D. Don) Otto ex DC.]; Erva; Sc: ESA

Mikania argyreiae DC.; Liana; Sc: ESA/SPSF

Mikania buddleiaefolia DC.; Liana; Sc: RB

Mikania guilleminii B. L. Rob.; Liana; Sc: ESA/SPSF

Mikania micrantha Kunth; Liana; Sc: RB

Mikania myriocephala DC.; Liana; Sc: ESA/SPSF

Mikania parodii Cabrera; Liana; Sc: ESA/SPSF

Mikania trinervis Hook. \& Arn.; Liana; Sc: NY

Piptocarpha axillaris (Less.) Baker; Árvore; Sc: ESA/HRCB/SPSF, 4, 5, 6, 8

Piptocarpha densifolia Dusén ex G. Lom. Sm.; Arbusto; Sc: NY

Piptocarpha macropoda (DC.) Baker; Árvore; Sc: ESA/UEC/SPSF, 4, 5, 6

Piptocarpha organensis Cabrera; Árvore; Sc: HRCB

Piptocarpha quadrangularis (Vell.) Baker; Arbusto; Sc: ESA

Piptocarpha regnellii (Sch. Bip.) Cabrera; Árvore; Sc: ESA/UEC

Pterocaulon alopecuroides (Lam.) DC.; Erva; Sc: ESA/SPSF

Pterocaulon balansae Chodat; Erva; Sc: ESA/UEC

Senecio brasiliensis (Spreng.) Less.; Erva; Sc: HRCB/UEC

Solidago chilensis Meyen; Erva; Sc: ESA/SPSF

Stifftia sp.; Arbusto; Sc: UEC

Trixis bowmanii Baker; Erva; Sc: IAC

Verbesina glabrata Hook. \& Arn.; Arbusto; Sc: ESA

Vernonanthura beyrichii (Less.) H.Rob. [=Vernonia beyrichii Less.]; Arbusto; Sc: SPSF

Vernonanthura discolor (Spreng.) H.Rob. [= Vernonia discolor (Spreng.) Less.]; Árvore; Sc: ESA, 4, 5

Vernonanthura divaricata (Spreng.) H.Rob. [= Vernonia diffusa Less.]; Árvore; Sc: HRCB/SPSF, 5

Vernonanthura lindbergii (Baker) H. Rob. [= Vernonia lindbergii Baker]; Arbusto; Sc: ESA

Vernonanthura petiolaris (DC.) H. Rob. [= Vernonia petiolaris DC.]; Árvore; Sc: NY

Vernonanthura puberula (Less.) H.Rob. [=Vernonia puberula Less]; Árvore; Sc: HRCB/SPSF, 4, 5, 6, 8

Vernonia densiflora Gardner; Árvore; Sc: ESA 
Lima, R.A.F. et al.

Apêndice 1. Continuação...

Família, espécie e autoria [sinonímia]

Wedelia subvelutina DC.; Erva; Sc: ESA

\section{BALANOPHORACEAE}

Lophophytum leandrii Eichler; Hemiparasita; Sc: TBB 578

\section{BEGONIACEAE}

Begonia angularis Raddi; Erva; Sc: ESA

Begonia capanemae Brade; Erva; Sc: ESA/SPSF, 6

Begonia fischeri Schrank; Erva; Sc: ESA/SPSF/SP

Begonia fruticosa (Klotzsch) A. DC.; Erva/epífito; Sc: ESA/SPSF/UEC/SP

Begonia herbacea Vell.; Epífito; Sc: TBB 529

Begonia inculta Irmsch.; Erva; Sc: RAFL 371

Begonia lanceolata Vell.; Epífito; Sc: ESA

Begonia pulchella Raddi; Erva; Sc: SP

Begonia radicans Vell.; Epífito; Sc: ESA/UEC/SPSF/SP

Begonia valdensium A. DC.; Erva; Sc: ESA/SPSF/SP

\section{BIGNONIACEAE}

Adenocalymma dusenii Kraenzl.; Liana; Sc: UEC

Adenocalymma hatschbachii A.H. Gentry; Liana; Sc: UEC

Adenocalymma paulistarum Bureau \& K. Schum.; Liana; Sc: UEC

Anemopaegma prostatum DC.; Liana; Sc: UEC

Arrabidaea multiflora Bureau \& K. Schum.; Liana; Sc: UEC

Bignonia binata Thunb. [= Clystostoma binatum (Thumb.) Sandwith]; Liana; Sc: UEC

Bignonia sciuripabula (K.Schum.) L.G. Lohmann; Liana; Sc: MO

Fridericia rego (Vell.) L.G. Lohmann [ Arrabidaea rego (Vell.) DC.]; Liana; Sc: UEC

Fridericia speciosa Mart.; Liana; Sc: ESA

Handroanthus albus (Cham.) Mattos; Árvore; Sc: MO

Handroanthus botelhensis (A.H. Gentry) S.O. Grose [= Tabebuia botelhensis A.H. Gentry]; Árvore; Sc: SPSF, 5

Handroanthus chrysotrichus (Mart. ex A. DC.) Mattos [= Tabebuia chrysotricha (Mart. \& A. DC.) Standley]; Árvore; Sc: UEC/SPSF

Handroanthus heptaphyllus (Vell.) Mattos [= Tabebuia heptaphylla (Vell.) Toledo]; Árvore; Sc: 2, 5

Handroanthus serratifolius (Vahl) S.O. Grose [= Tabebuia serratifolia (Vahl) Nicholson]; Árvore; Sc: ESA, 6

Jacaranda micrantha Cham.; Árvore; Sc: UEC, OTA 880

Jacaranda montana Morawetz; Árvore; Sc: ESA, 2, 6

Jacaranda puberula Cham.; Árvore; Sc: ESA/SPSF/UEC, 4, 5, 8

Lundia cf. virginalis DC.; Liana; Sc: SPSF

Mansoa lanceolata (DC.) A.H. Gentry [=Anemopaegma lanceolatum (DC.) Bureau ex K. Schum.]; Lf: liana; Sc: ESA, 2

Parabignonia unguiculata (Vell.) A.H. Gentry; Liana; Sc: SPSF

Paragonia pyramidata (Rich.) Bureau; Liana; Sc: 2, MBM

Pithecoctenium crucigerum (L.) A.H. Gentry; Liana; Sc: ESA

BORAGINACEAE (inclui Cordiaceae e Heliotropiaceae)

Cordia ecalyculata Vell.; Árvore; Sc: ESA, 2

Cordia magnoliifolia Cham.; Árvore; Sc: SPSF

Cordia sellowiana Cham.; Árvore; Sc: ESA, 6

Cordia silvestris Fresen.; Árvore; Sc: ESA 
Família, espécie e autoria [sinonímia]

Cordia trichotoma (Vell.) Arrab.ex Steud; Árvore; Sc: ESA, 4, 5, 8, 9

Heliotropium transalpinum Vell.; Erva; Sc: ESA

Varronia discolor (Cham. \& Schltdl.) Borhidi [= Cordia discolor Cham. \& Schltdl.]; Arbusto; Sc: ESA

Varronia polycephala Lam. [= Cordia monosperma (Jacq.) Roem. \& Schult.]; Arbusto; Sc: ESA

BURSERACEAE

Protium kleinii Cuatrec. [ P. heptaphyllum (Aubl.) Marchand]; Árvore; Sc: ESA

Protium widgrenii Engl. [ P. heptaphyllum (Aubl.) Marchand]; Árvore; Sc: ESA, 4, 5

\section{CACTACEAE}

Hatiora salicornioides (Haw.) Britton \& Rose; Epífito; Sc: ESA, TBB 471

Lepismium cruciforme (Vell.) Miq.; Epífito; Sc: TBB 644

Lepismium houlletianum (Lem.) Barthlott; Epífito; Sc: TBB 522

Pereskia aculeata Mill.; Epífito; Sc: 1

Rhipsalis campos-portoana Loefgr.; Epífito; Sc: SPSF

Rhipsalis dissimilis (G. Lindb.) K. Schum.; Epífito; Sc: ESA

Rhipsalis elliptica G. Lindb. ex K. Schum.; Epífito; Sc: ESA/SPSF, TBB 160

Rhipsalis floccosa Salm.-Dyck ex Pfeiff.; Epífito; Sc: ESA

Rhipsalis grandiflora Haw.; Epífito; Sc: TBB 544

Rhipsalis juengeri Barthlott \& N.P. Taylor; Epífito; Sc: UEC

Rhipsalis pachyptera Pfeiff.; Epífito; Sc: TBB 163

Rhipsalis paradoxa (Salm-Dyck ex Pfeiff.) Salm-Dyck; Epífito; Sc: TBB 451

Rhipsalis pilocarpa Loefgr.; Epífito; Sc: 1

Rhipsalis puniceodiscus G. Lindb.; Epífito; Sc: ESA, TBB 616

Rhipsalis teres (Vell.) Steud.; Epífito; Sc: ESA/SPSF, TBB 150

\section{CAMPANULACEAE}

Centropogon cornutus (L.) Druce; Erva; Sc: ESA

Siphocampylus convolvulaceus (Cham.) G. Don; Liana; Sc: ESA/SPSF

\section{CANELLACEAE}

Cinnamodendron dinisii Schwacke [= Capsicodendron dinisii]; Árvore; Sc: ESA/SPSF, 4, 5, 7, 8, 9

\section{CANNABACEAE}

Trema micrantha (L.) Blume; Árvore; Sc: UEC/SPSF/IAC

\section{CARDIOPTERIDACEAE}

Citronella paniculata (Mart.) R.A. Howard [= C. megaphylla (Miers) R.A. Howard]; Árvore; Sc: ESA, 4, 6, 8, 9

\section{CARICACEAE}

Jacaratia spinosa (Aubl.) A. DC.; Árvore; Sc: ESA

\section{CELASTRACEAE}

Cleiloclinium cognatum (Miers) A.C. Sm.; Liana; Sc: OTA 1035, 1348

Hippocratea volubilis L.; Liana; Sc: ESA

Maytenus aquifolia Mart.; Árvore; Sc: VCS 30023

Maytenus communis Reissek; Árvore; Sc: ESA/SPSF

Maytenus robusta Reissek; Árvore; Sc: ESA, 4, 6

Maytenus salicifolia Reissek; Árvore; Sc: ESA

Maytenus schumanniana Loes.; Arbusto; Sc: SPSF, RAFL 380

Salacia elliptica (Mart. ex Schult.) G. Don; Liana; Sc: ESA 
Lima, R.A.F. et al.

Apêndice 1. Continuação...

Família, espécie e autoria [sinonímia]

Tontelea tenuicula (Miers) A.C. Sm.; Liana; Sc: UEC

CHLORANTHACEAE

Hedyosmum brasiliense Miq.; Árvore; Sc: RAFL 320

CHRYSOBALANACEAE

Hirtella hebeclada Moric. ex DC.; Árvore; Sc: ESA/UEC, 4, 5, 6

Licania hoehnei Pilg.; Árvore; Sc: 4, 5, 6

Licania octandra (Hoffmanns. ex Roem. \& Schult.) Kuntze; Árvore; Sc: VCS 29313

Parinari brasiliensis (Schott) Hook. f. [ P. excelsa Sabine]; Árvore; Sc: 4, 6, VCS 30028

CLETHRACEAE

Clethra scabra Pers. [= C. brasiliensis Cham. \& Schltdl.]; Árvore; Sc: ESA/SPSF, 4, 5, 6, 9

\section{CLUSIACEAE}

Clusia criuva subsp. parviflora Vesque [= C. parviflora Saldanha ex Engl.]; Epífito; Sc: ESA/SPSF/UEC, 4, 5, 8

Garcinia gardneriana (Planch. \& Triana) Zappi; Árvore; Sc: 6, VCS 29370

COMBRETACEAE

Buchenavia hoehneana N.F. Mattos; Árvore; Sc: IAC

Buchenavia kleinii Exell; Árvore; Sc: 5, 6, VCS 30030

Terminalia triflora (Griseb.) Lillo.; Árvore; Sc: 4, 5

CONNARACEAE

Connarus rostratus (Vell.) L.B. Sm.; Liana; Sc: RAFL 591

CONVOLVULACEAE

Ipomoea ramosissima (Poir.) Choisy; Liana; Sc: ESA/SPSF/UEC

Ipomoea tiliacea (Willd.) Choisy; Liana; Sc: ESA/SPSF/UEC

CUCURBITACEAE

Cayaponia cabocla Cogn.; Liana; Sc: NY

Fevillea passiflora Vell.; Liana; Sc: SPSF

Gurania cissoides (Benth.) Cogn.; Liana; Sc: ESA

Wilbrandia hibiscoides Silva Manso; Liana; Sc: ESA

CUNONIACEAE

Lamanonia ternata Vell. [= L. speciosa (Cambess) L.B. Smith]; Árvore; Sc: ESA, 5, 6

Weinmannia discolor Gardner; Árvore; Sc: ESA, 5

Weinmannia paulliniifolia Pohl ex Ser.; Árvore; Sc: 4, 5, 6, OTA 1394, 1408

DILLENIACEAE

Doliocarpus dentatus (Aubl.) Standl.; Liana; Sc: ESA

ELAEOCARPACEAE

Sloanea guianensis (Aubl.) Benth.; Árvore; Sc: VCS 30033

Sloanea hirsuta (Schott) Planch. ex Benth. [= S. monosperma Vell.]; Árvore; Sc: SPSF, VCS 30034

Sloanea obtusifolia (Moric.) K. Schum.; Árvore; Sc: ESA

ERYTHROXYLACEAE

Erythroxylum ambiguum Peyr.; Arbusto; Sc: ESA/SPSF, 6

Erythroxylum cuspidifolium Mart.; Arbusto; Sc: RAFL 809

Erythroxylum pulchrum A. St.-Hil.; Arbusto; Sc: 5

EUPHORBIACEAE (inclui Peraceae)

Actinostemon concolor (Spreng.) Müll. Arg. [= Gymnanthes concolor Spreng.]; Árvore; Sc: ESA, 5, 8 
Família, espécie e autoria [sinonímia]

Alchornea glandulosa Poepp. \& Endl.; Árvore; Sc: VCS 30041

Alchornea triplinervia (Spreng.) Müll. Arg.; Árvore; Sc: SPSF/SP, 4, 5, 6, 7, RAFL 807

Aparisthmium cordatum (A. Juss.) Baill.; Árvore; Sc: ESA, 2

Croton glandulosus L.; Erva; Sc: ESA/UEC

Croton lundianus (Didr.) Müll. Arg.; Arbusto; Sc: SPSF/SPF

Croton macrobothrys Baill.; Árvore; Sc: VCS 30042

Manihot grahamii Hook.; Árvore; Sc: VCS 29277, 29278

Maprounea guianensis Aubl.; Árvore; Sc: 1

Pera glabrata (Schott) Poepp. ex Baill.; Árvore; Sc: ESA/UEC, 5, 8

Pera obovata (Klotzsch) Baill.; Árvore; Sc: 5

Sapium glandulosum (L.) Morong; Árvore; Sc: ESA/SPSF/IAC/SP, 4, 5

Sebastiania brasiliensis (L.) Spreng.; Sc: ESA

Tetrorchidium parvulum Müll. Arg.; Árvore; Sc: 2

Tetrorchidium rubrivenium Poepp.; Árvore; Sc: 6, VCS 30047

\section{FABACEAE}

Abarema langsdorffii (Benth.) Barneby \& J.W. Grimes [= Pithecellobium langsdorffii Benth.]; Árvore; Sc: ESA/IAC/SPSF, 4, 5, 8, 9

Albizia pedicellaris (DC.) L. Rico [= Balizia pedicellaris (DC.) Barneby \& J. W. Grimes]; Árvore; Sc: UEC

Andira anthelmia (Vell.) J.F. Macbr. [= A. anthelminthica (Vog.) Benth.]; Árvore; Sc: ESA/SPSF/IAC

Andira fraxinifolia Benth.; Árvore; Sc: ESA/SPSF

Bauhinia guianensis Aubl.; Liana; Sc: ESA/UEC

Calliandra sp.; Arbusto; Sc: ESA

Cassia ferruginea (Schrad.) Schrad. ex DC.; Árvore; Sc: ESA

Centrolobium robustum (Vell.) Mart. ex Benth.; Árvore; Sc: ESA, 8

Copaifera langsdorffii Desf.; Árvore; Sc: ESA, 5, 6, 8

Copaifera trapezifolia Hayne; Árvore; Sc: ESA, 4, 5, 6, 7, 8

Dahlstedtia pentaphylla (Taub.) Burkart; Arbusto; Sc: ESA, OTA 1358

Dahlstedtia pinnata (Benth.) Malme; Árvore; Sc: ESA/SPSF, 5

Dalbergia brasiliensis Vogel; Árvore; Sc: ESA/SPSF

Dalbergia frutescens (Vell.) Britton; Árvore/Liana; Sc: ESA, 4, 5, 6

Desmodium adscendens (Sw.) DC.; Erva; Sc: ESA/SPSF/UEC

Desmodium axillare (Sw.) DC.; Erva; Sc: UEC

Desmodium incanum DC.; Erva; Sc: ESA/UEC

Desmodium uncinatum (Jacq.) DC.; Erva; Sc: ESA/UEC

Eriosema heterophyllum Benth.; Erva; Sc: UEC

Erythrina speciosa Andrews; Arbusto; Sc: SPSF

Hymenaea courbaril L. [= H. altissima Ducke]; Árvore; Sc: ESA, 5

Inga capitata Desv.; Árvore; Sc: 6

Inga cylindrica (Vell.) Mart.; Árvore; Sc: SPSF

Inga edulis Mart.; Árvore; Sc: SPSF

Inga laurina (Sw.) Willd.; Árvore; Sc: SPSF/RB, 4

Inga lenticellata Benth.; Árvore; Sc: ESA/SPSF

Inga marginata Willd.; Árvore; Sc: ESA/SPSF, 4, 5, 8 
Lima, R.A.F. et al.

Apêndice 1. Continuação...

Família, espécie e autoria [sinonímia]

Inga praegnans T.D. Penn.; Árvore; Sc: ESA/SPSF

Inga sellowiana Benth.; Árvore; Sc: ESA/SPSF, 4, 5, 6

Inga sessilis (Vell.) Mart.; Árvore; Sc: ESA/SPSF/UEC, 4, 5, 6

Lonchocarpus nitidus (Vogel) Benth.; Árvore; Sc: ESA

Machaerium dimorphandrum Hoehne; Árvore/Liana; Sc: VCS 29239

Machaerium nyctitans (Vell.) Benth.; Árvore; Sc: ESA, 4, 5

Machaerium oblongifolium Vogel; Árvore; Sc: UEC

Machaerium triste Vogel; Liana; Sc: UEC, RAFL 528

Machaerium uncinatum (Vell.) Benth.; Árvore; Sc: ESA/UEC

Mimosa scabrella Benth.; Árvore; Sc: RB

Mucuna urens (L.) Medik.; Liana; Sc: SPSF

Myrocarpus frondosus Allemão; Árvore; Sc: ESA/UEC, 4, 5, 6, 7

Ormosia arborea (Vell.) Harms; Árvore; Sc: ESA

Ormosia minor Vogel [= O. dasycarpa var. minor (Vogel) Benth.]; Árvore; Sc: ESA, 5, 6, OTA 1376

Phanera microstachya (Raddi) L.P.Queiroz [= Bauhinia microstachya (Raddi) J.F. Macbr.]; Liana; Sc: RB

Piptadenia paniculata Benth.; Árvore; Sc: VCS 30102

Platymiscium floribundum Vogel; Árvore; Sc: 4, 5, 9, VCS 30058

Pseudopiptadenia warmingii (Benth.) G.P. Lewis \& M.P. Lima; Árvore; Sc: VCS 29247

Pterocarpus rohrii Vahl; Árvore; Sc: ESA/SPSF, 4, 5, 6, 8

Schizolobium parahyba (Vell.) Blake.; Árvore; Sc: ESA, 5, 8

Senegalia grandistipula (Benth.) Seigler \& Ebinger [= Acacia grandistipula Benth.]; Liana; Sc: ESA/SPSF

Senegalia lacerans (Benth.) Seigler \& Ebinger [= Acacia lacerans Benth.]; Liana; Sc: ESA/UEC

Senegalia lowei (L. Rico) Seigler \& Ebinger [= Acacia plumosa Lowe]; Liana; Sc: ESA

Senegalia martiusiana (Steud.) Seigler \& Ebinger [= Acacia martiusiana (Steud.) Burkart]; Liana; Sc: RB

Senna macranthera (DC. ex Collad.) H.S. Irwin \& Barneby; Árvore; Sc: ESA

Senna multijuga (Rich.) H.S. Irwin \& Barneby; Árvore; Sc: ESA/SPSF, 4, 5

Stylosanthes viscosa (L.) Sw.; Erva; Sc: ESA/SPSF

Swartzia oblata R.S. Cowan [ S. acutifolia Vogel]; Árvore; Sc: ESA/SPSF/UEC

Tachigali denudata (Vogel) Oliveira-Filho [= Sclerolobium denudatum Vogel]; Árvore; Sc: 4, 5, 6, 7, OTA 1385

Zollernia ilicifolia (Brongn.) Vogel; Árvore; Sc: ESA/UEC, 4, 5, 6, 7, 8

GENTIANACEAE

Macrocarpaea rubra Malme; Erva; Sc: ESA/SPSF/UEC

Voyria aphylla (Jacq.) Pers.; Erva; Sc: ESA

\section{GESNERIACEAE}

Codonanthe devosiana Lem.; Epífito; Sc: UEC, TBB 472

Codonanthe gracilis (Mart.) Hanst.; Epífito; Sc: ESA/SPSF/UEC, TBB 1070

Napeanthus primulifolius (Raddi) Sandwith; Erva; Sc: ESA

Nematanthus gregarius D. L. Denham; Epífito; Sc: UEC/SPSF, TBB 1071

Nematanthus jolyanus (Handro) Chautems; Epífito; Sc: SPSF

Nematanthus striatus (Handro) Chautems; Epífito; Sc: ESA/SPSF/UEC, TBB 1088

Nematanthus strigillosus (Mart.) H.E. Moore; Epífito; Sc: UEC/SPSF

Nematanthus villosus (Hanst.) Wiehler; Epífito; Sc: UEC

Nematanthus wettsteinii (Fritsch) H.E.Moore; Epífito; Sc: ESA/UEC 


\section{Família, espécie e autoria [sinonímia]}

Sinningia douglasii (Lindl.) Chautems; Epífito; Sc: ESA/UEC

HUMIRIACEAE

Humiriastrum dentatum (Casar.) Cuatrec.; Árvore; Sc: IAC

Vantanea compacta (Schnizl.) Cuatrec.; Árvore; Sc: ESA, 4, 5, 6

\section{HYPERICACEAE}

Hypericum brasiliense Choisy; Erva; Sc: SPSF

\section{LACISTEMATACEAE}

Lacistema lucidum Schnizl.; Arbusto; Sc: UEC

\section{LAMIACEAE}

Aegiphila brachiata Vell.; Árvore; Sc: 4, OTA 1360

Aegiphila integrifolia (Jacq.) B.D. Jacks [= A. sellowiana Cham.]; Árvore; Sc: SPSF, 4, 5

Aegiphila obducta Vell.; Árvore; Sc: SPSF

Hyptis lacustris A. St.-Hil. ex Benth.; Erva; Sc: ESA/SPSF

Hyptis multibracteata Benth.; Erva; Sc: ESA

Hyptis sidifolia (L’Hér.) Briq. [= H. umbrosa Salzm. ex Benth.]; Erva; Sc: ESA/SPSF

Marsypianthes chamaedrys (Vahl) Kuntze; Erva; Sc: ESA

Ocimum carnosum (Spreng.) Link \& Otto ex Benth. [= O. selloi Benth.]; Erva; Sc: ESA/SPSF

Peltodon radicans Pohl; Erva; Sc: ESA/SPSF

Scutellaria uliginosa A. St.-Hil. eax Benth.; Erva; Sc: ESA/SPSF

Vitex cymosa Bertero ex Spreng.; Árvore; Sc: 2

Vitex polygama Cham.; Árvore; Sc: SPSF, 4, 5

\section{LAURACEAE}

Aiouea acarodomatifera Kosterm.; Árvore; Sc: SPSF

Aiouea saligna Meisn.; Árvore; Sc: ESA/UEC

Aniba firmula (Nees \& Mart.) Mez; Árvore; Sc: ESA/SPSF/UEC, 4, 5

Aniba viridis Mez; Árvore; Sc: ESA, 6

Beilschmiedia emarginata (Meisn.) Kosterm.; Árvore; Sc: OTA 1357

Cinnamomum hirsutum Lorea-Hern.; Árvore; Sc: ESA

Cinnamomum pseudoglaziovii Lorea-Hern.; Árvore; Sc: ESA/SPSF

Cinnamomum triplinerve (Ruiz \& Pav.) Kosterm.; Árvore; Sc: RAFL 218, OTA 1392

Cryptocarya aschersoniana Mez; Árvore; Sc: 4, 5, 6

Cryptocarya botelhensis P.L.R. de Moraes; Árvore; Sc: ESA/UEC, OTA 1372

Cryptocarya mandioccana Meisn. [ C. moschata Nees]; Árvore; Sc: ESA/SPSF, 4, 7

Cryptocarya saligna Mez; Árvore; Sc: 1

Endlicheria paniculata (Spreng.) J.F. Macbr.; Árvore; Sc: ESA/SPSF/UEC, 4, 5, 6, 8

Licaria armeniaca (Nees) Kosterm.; Árvore; Sc: ESA

Nectandra debilis Mez; Árvore; Sc: SPSF

Nectandra grandiflora Nees; Árvore; Sc: 5, 8

Nectandra lanceolata Nees; Árvore; Sc: ESA

Nectandra leucantha Nees; Árvore; Sc: ESA

Nectandra membranacea (Sw.) Griseb.; Árvore; Sc: ESA/SPSF

Nectandra oppositifolia Nees [= N. mollis var. oppositifolia (Nees) Rohwer]; Árvore; Sc: ESA/SPSF, 4, 5, 6

Nectandra paranaensis Coe-Teix.; Árvore; Sc: SPSF 
Lima, R.A.F. et al.

Apêndice 1. Continuação...

Família, espécie e autoria [sinonímia]

Nectandra puberula (Schott) Nees; Árvore; Sc: 5

Nectandra reticulata (Ruiz \& Pav.) Mez [= N. mollis (Kunth) Nees]; Árvore; Sc: VCS 29211

Ocotea aciphylla (Nees \& Mart.) Mez; Árvore; Sc: ESA/SPSF, 4, 5, 6

Ocotea bicolor Vattimo-Gil; Árvore; Sc: ESA/SPSF, 4, 5, 6

Ocotea brachybotrya (Meisn.) Mez; Árvore; Sc: ESA/SPSF, 4, 5, 6, 8

Ocotea catharinensis Mez; Árvore; Sc: ESA/SPSF, 4, 5, 6, 7

Ocotea cf. bragai Coe-Teix.; Árvore; Sc: OTA 1350

Ocotea corymbosa (Meisn.) Mez; Árvore; Sc: 5

Ocotea daphnifolia (Meisn.) Mez; Árvore; Sc: UEC, 6, VCS 29222

Ocotea dispersa (Nees \& Mart.) Mez; Árvore; Sc: ESA/SPSF, 4, 5, 6

Ocotea divaricata (Nees) Mez; Árvore; Sc: ESA, 5

Ocotea elegans Mez; Árvore; Sc: ESA/SPSF, 4, 5, 6, 8

Ocotea glaziovii Mez; Árvore; Sc: ESA, 4, 5, 6, 7

Ocotea lancifolia (Schott) Mez; Árvore; Sc: OTA 1395

Ocotea laxa (Nees) Mez; Árvore; Sc: MBM, 5

Ocotea mosenii Mez; Árvore; Sc: SPSF

Ocotea nectandrifolia Mez [= O. kuhlmanii Vattimo-Gil.]; Árvore; Sc: ESA/SPSF, 4, 57

Ocotea nunesiana (Vattimo-Gil) Baitello; Árvore; Sc: RAFL 811

Ocotea odorifera (Vell.) Rohwer [= O. pretiosa (Nees) Mez]; Árvore; Sc: ESA/SPSF, 4, 5, OTA 1374

Ocotea paranapiacabensis Coe-Teixeira; Árvore; Sc: 5

Ocotea porosa (Nees \& Mart.) Barroso; Árvore; Sc: ESA

Ocotea puberula (Rich.) Nees; Árvore; Sc: 5

Ocotea pulchella (Nees \& Mart.) Mez; Árvore; Sc: ESA/SPSF, 5, 7

Ocotea pulchra Vattimo-Gil; Árvore; Sc: ESA/SPSF, 4, 5, 6

Ocotea silvestris Vattimo-Gil; Árvore; Sc: ESA/SPSF, 4, 5, 6

Ocotea tabacifolia (Meisn.) Rohwer; Árvore; Sc: UEC/SPSF, OTA 1406

Ocotea teleiandra (Meisn.) Mez; Árvore; Sc: ESA/SPSF/UEC, 6

Ocotea venulosa (Nees) Baitello; Árvore; Sc: ESA

Persea rufotomentosa Nees \& Mart.; Árvore; Sc: OTA 1370, 1371

Persea venosa Nees \& Mart.; Árvore; Sc: ESA

Persea willdenovii Kosterm. [= P. pyrifolia Nees \& Mart.]; Árvore; Sc: ESA, 6

Rhodostemonodaphne macrocalyx (Meisn.) Rohwer ex Madriñan; Árvore; Sc: ESA

LECYTHIDACEAE

Cariniana estrellensis (Raddi) Kuntze; Árvore; Sc: ESA, 5, 7, 8

\section{LOGANIACEAE}

Spigelia beyrichiana Cham. \& Schltdl. [= S. dusenii L.B. Sm.]; Erva; Sc: ESA/SPSF

Strychnos brasiliensis Mart.; Arbusto; Sc: ESA

Strychnos trinervis (Vell.) Mart. [= S. triplinervia Mart.]; Liana; Sc: ESA/SPSF, 7

\section{LORANTHACEAE}

Psittacanthus brasiliensis (Desr.) G. Don [= P. flavo-viridis Eichler]; Hemiparasita; Sc: ESA

Psittacanthus dichroos (Mart.) Mart.; Hemiparasita; Sc: ESA

Struthanthus marginatus (Desr.) Blume; Hemiparasita; Sc: TBB 536

Struthanthus concinnus Mart.; Hemiparasita; Sc: ESA/SPSF 


\section{Família, espécie e autoria [sinonímia]}

Struthanthus hartwegii (Benth.) Standl. [= S. rotundatus Rizzini]; Hemiparasita; Sc: SPSF

Struthanthus polyrhizos (Mart.) Mart.; Hemiparasita; Sc: ESA

Struthanthus vulgaris Mart. \& Eichl.; Hemiparasita; Sc: ESA

\section{LYTHRACEAE}

Cuphea calophylla Cham. \& Schltdl. subsp. calophylla; Erva; Sc: ESA/SPSF

Heimia myrtifolia Cham. \& Schltdl.; Erva; Sc: ESA/SPSF

\section{MAGNOLIACEAE}

Magnolia ovata (A. St.-Hil.) Spreng. [= Talauma ovata A. St.-Hil.]; Árvore; Sc: ESA, 5, 8, 9

\section{MALPIGHIACEAE}

Banisteriopsis argyrophylla (A. Juss.) B. Gates; Liana; Sc: ESA/SPSF

Bunchosia fluminensis Griseb.; Árvore; Sc: ESA

Byrsonima ligustrifolia A. Juss.; Árvore; Sc: ESA/SPSF/UEC, 4, 5, 6, 8

Byrsonima myricifolia Griseb; Árvore; Sc: SPSF/SP

Heteropterys fluminensis (Griseb.) W.R. Anderson; Liana; Sc: SP

Heteropterys intermedia (A. Juss.) Griseb.; Liana; Sc: SPSF/SP

Heteropterys nitida (Lam.) Kunth; Liana; Sc: SPSF/SP

Hiraea gaudichaudiana A. Juss.; Liana; Sc: SP

Stigmaphyllon puberulum Griseb.; Liana; Sc: ESA/SPSF/UEC

Stigmaphyllon tomentosum A. Juss.; Liana; Sc: SP

Tetrapterys phlomoides (Spreng.) Nied.; Liana; Sc: UEC/SPSF

\section{MALVACEAE}

Abutilon rufinerve A. St.-Hil.; Árvore; Sc: SPSF

Eriotheca pentaphylla (Vell.) A. Robyns; Árvore; Sc: 1

Pavonia dusenii Krapov.; Erva; Sc: SP/NY

Pseudobombax grandiflorum (Cav.) A. Robyns; Árvore; Sc: 1

Quararibea turbinata (Sw.) Poir.; Árvore; Sc: ESA

Sida rhombifolia L.; Erva; Sc: ESA/SPSF/UEC

Spirotheca rivierii (Decne.) Ulbr. [= S. passifloroides Cuatrec.]; Epífito; Sc: ESA, 5, 7, TBB 785

Triumfetta guaranitica Villa; Arbusto; Sc: ESA

Triumfetta semitriloba Jacq.; Arbusto; Sc: SPSF

\section{MARCGRAVIACEAE}

Marcgravia polyantha Delpino; Epífito; Sc: ESA/UEC/SPSF

Schwartzia brasiliensis (Choisy) Bedell ex Gir.-Cañas [= Norantea brasiliensis Choisy]; Epífito; Sc: ESA

\section{MELASTOMATACEAE}

Aciotis paludosa (Mart. ex DC.) Triana [= A. brachybotrya DC.]; Erva; Sc: ESA/SPSF

Bertolonia acuminata Gardner; Erva; Sc: ESA/SPSF

Bertolonia mosenii Cogn.; Erva/epífito; Sc: ESA/SPSF/UEC, TBB 787

Clidemia biserrata DC.; Arbusto; Sc: ESA/SPSF

Clidemia hirta (L.) D. Don; Arbusto; Sc: ESA, TBB 793

Henriettella glabra Cogn. [ Mouriri sagotiana Triana]; Árvore; Sc: SPSF/NY

Leandra acutiflora (Naudin) Cogn.; Arbusto; Sc: ESA/SPSF

Leandra amplexicaulis DC.; Arbusto; Sc: UEC

Leandra australis (Cham.) Cogn. [= L. atropurpurea Cogn.]; Arbusto; Sc: NY 
Lima, R.A.F. et al.

Apêndice 1. Continuação...

Família, espécie e autoria [sinonímia]

Leandra balansaei Cogn.; Arbusto; Sc: ESA

Leandra cardiophylla Cogn.; Erva; Sc: ESA

Leandra refracta Cogn.; Erva; Sc: ESA/IF

Leandra dasytricha (A. Gray) Cogn. [ L. mosenii Cogn.]; Árvore; Sc: ESA/SPSF, 5

Leandra fallax (Cham.) Cogn.; Arbusto; Sc: SPSF/UEC

Leandra fragilis Cogn.; Erva; Sc: ESA/SPSF

Leandra gracilis Cogn.; Arbusto; Sc: HRCB

Leandra laevigata (Triana) Cogn.; Arbusto; Sc: ESA/SPSF

Leandra melastomoides Raddi [= L. scabra DC.]; Arbusto; Sc: ESA/SPSF

Leandra pilonensis Wurdack; Arbusto; Sc: 4, RAFL 191

Leandra regnellii (Triana) Cogn. [=L. alterninervia Cogn.]; Arbusto; Sc: ESA/SPSF

Leandra reversa (DC.) Cogn.; Arbusto; Sc: SPSF

Leandra sabiaensis Brade; Arbusto; Sc: RAFL 192

Leandra tetraquetra Cogn.; Arbusto; Sc: IAC

Leandra xanthocoma (Naudin) Cogn.; Erva; Sc: ESA

Meriania claussenii (Naudin) Triana; Árvore; Sc: ESA

Meriania sanchezii R. Goldenb. [ M. glabra (DC.) Triana]; Árvore; Sc: VCS 30091

Miconia cabucu Hoehne; Árvore; Sc: ESA/IAC/UEC/SPSF, 4, 5, 6

Miconia cinerascens var. robusta Wurdack; Arbusto; Sc: UEC

Miconia cinnamomifolia (DC.) Naudin; Árvore; Sc: RAFL 412

Miconia cubatanensis Hoehne; Árvore; Sc: SPSF, 6, VCS 30094

Miconia doriana Cogn.; Erva; Sc: ESA/UEC, 6

Miconia fasciculata Gardner.; Arbusto; Sc: ESA/SPSF/UEC

Miconia latecrenata (DC.) Naud.; Arbusto; Sc: ESA/SPSF/UEC

Miconia petropolitana Cogn.; Arbusto; Sc: ESA/SPSF/UEC, 6

Miconia pusilliflora (DC.) Triana [= M. hymenonervia Cogn., M. rigidiuscula Cogn.]; Arbusto; Sc: ESA/UEC, 6

Miconia racemifera (DC.) Triana; Árvore; Sc: SPSF, 6

Miconia sellowiana Naudin; Arbusto; Sc: ESA, 6

Miconia theaezans (Bonpl.) Cogn.; Arbusto; Sc: ESA/IAC/UEC/SPSF, 4, 5, 6

Miconia tristis subsp. australis Wurdack; Árvore; Sc: ESA/UEC

Miconia valtheri Naud.; Árvore; Sc: ESA/UEC/SPSF, 6

Mouriri chamissoana Cogn.; Árvore; Sc: VCS 30095

Ossaea cf. confertiflora (DC.) Triana; Arbusto; Sc: RAFL 415

Ossaea sanguinea Cogn.; Arbusto; Sc: ESA/UEC

Pleiochiton blepharodes (DC.) Reginato et al. [= Clidemia blepharodes DC.]; Erva/epífito; Sc: ESA/SPSF, TBB 775

Pleiochiton ebracteatum Triana; Epífito; Sc: ESA/UEC, TBB 1100

Pterolepis glomerata (Rottb.) Miq.; Erva; Sc: ESA/UEC

Salpinga margaritacea (Naudin) Triana; Erva/epífito; Sc: ESA/UEC, TBB 788

Tibouchina cerastifolia Cogn.; Erva; Sc: ESA/UEC

Tibouchina clinopodifolia (DC.) Cogn.; Erva; Sc: ESA/UEC

Tibouchina fothergillae (DC.) Cogn.; Árvore; Sc: ESA/UEC

Tibouchina gracilis (Bonpl.) Cogn.; Arbusto; Sc: R

Tibouchina mutabilis (Vell.) Cogn. [ T. raddiana (DC.) Cogn.]; Árvore; Sc: ESA/RB 
Família, espécie e autoria [sinonímia]

Tibouchina pulchra (Cham.) Cogn.; Árvore; Sc: SPSF, 4, 5, 6

Tibouchina sellowiana (Cham.) Cogn.; Árvore; Sc: IAC, OTA 1380

MELIACEAE

Cabralea canjerana (Vell.) Mart. subsp. canjerana; Árvore; Sc: ESA/SPSF, 2, 4, 5, 6, 7, 8

Cedrela fissilis Vell.; Árvore; Sc: ESA/SPSF/UEC, 4, 5, 7, 8

Cedrela odorata L.; Árvore; Sc: SPSF

Guarea macrophylla subsp. tuberculata (Vell.) T.D. Penn.; Árvore; Sc: ESA, 2, 5, 6, 8

Trichilia elegans A. Juss. subsp. elegans; Árvore; Sc: 2

Trichilia lepidota Mart.; Árvore; Sc: VCS 30097

Trichilia pallens C. DC.; Árvore; Sc: VCS 29233

Trichilia silvatica C. DC.; Árvore; Sc: 1

\section{MENISPERMACEAE}

Abuta selloana Eichler; Liana; Sc: ESA/UEC

Cissampelos andromorpha DC.; Liana; Sc: ESA

Cissampelos pareira L.; Liana; Sc: UEC

MONIMIACEAE

Mollinedia argyrogyna Perkins; Árvore; Sc: SPSF, OTA 1388

Mollinedia boracensis Peixoto; Arbusto; Sc: ESA

Mollinedia elegans Tul.; Árvore; Sc: ESA, 6, OTA 1387

Mollinedia gilgiana Perkins; Árvore; Sc: ESA

Mollinedia luizae Peixoto; Árvore; Sc: ESA

Mollinedia micrantha Perkins; Arbusto; Sc: VCS 30105

Mollinedia oligantha Perkins; Árvore; Sc: RB, 5, 6, OTA 872

Mollinedia oligotricha Perkins; Árvore; Sc: SPSF, 5, OTA 1389

Mollinedia pachysandra Perkins; Árvore; Sc: SPSF

Mollinedia schottiana (Spreng.) Perkins; Árvore; Sc: ESA/UEC/SPSF, 4, 5, 6, 8

Mollinedia triflora (Spreng.) Tul.; Arbusto; Sc: SPSF

Mollinedia uleana Perkins; Árvore; Sc: UEC/SPSF, VCS 29264

Mollinedia widgrenii A. DC.; Árvore; Sc: 5

\section{MORACEAE}

Brosimum glaziovii Taub.; Árvore; Sc: VCS 30119

Brosimum guianense (Aubl.) Huber; Árvore; Sc: SPSF

Dorstenia hirta Desv.; Erva; Sc: ESA

Ficus gomelleira Kunth \& Bouché; Árvore; Sc: ESA/SPSF

Ficus guaranitica Chodat.; Epífito; Sc: VCS 29265

Ficus insipida Willd.; Árvore; Sc: VCS 30121

Ficus luschnatiana (Miq.) Miq.; Árvore/ hemi-epífito; Sc: ESA/SPSF, 2, 4, 5

Sorocea bonplandii (Baill.) W. Burg., Lanj. \& Wess. Bo. [= S. ilicifolia Miq.]; Árvore; Sc: ESA/SPSF, 4, 5, 6

Sorocea jureiana Romaniuc; Árvore; Sc: RAFL 806

\section{MYRISTICACEAE}

Virola bicuhyba (Schott) Warb. [= V. oleifera (Schott) Smith]; Árvore; Sc: 4, 8, VCS 29369

Virola gardneri (A. DC.) Warb.; Árvore; Sc: VCS 29260

\section{MYRTACEAE}

Calyptranthes lanceolata O. Berg; Árvore; Sc: ESA, 6 
Lima, R.A.F. et al.

Apêndice 1. Continuação...

Família, espécie e autoria [sinonímia]

Calyptranthes lucida Mart. ex. DC.; Árvore; Sc: OTA 1369

Calyptranthes cf. obovata Kiaersk.; Árvore; Sc: OTA 1383

Calypthranthes sp.; Árvore; Sc: OTA 1396

Campomanesia eugenioides (Cambess.) D. Legrand; Árvore; Sc: ESA

Campomanesia guaviroba (DC.) Kiaersk.; Árvore; Sc: ESA/UEC/SP, 4, 5, 7, 8

Campomanesia phaea (O. Berg) Landrum; Árvore; Sc: ESA/SP

Campomanesia schlechtendaliana (O. Berg) Nied.; Árvore; Sc: OTA 1351

Campomanesia xanthocarpa (Mart.) O. Berg; Árvore; Sc: SPSF/SP, 7

Eugenia acutata Miq. [= Calycorectes acutatus (Miq.) Toledo]; Árvore; Sc: SPSF

Eugenia bacopari D. Legrand; Árvore; Sc: SP

Eugenia bocainensis Mattos; Arbusto; Sc: RAFL 435

Eugenia brevistyla D. Legrand [=Calycorectes australis D. Legrand]; Árvore; Sc: ESA

Eugenia bunchosifolia Nied [= E. santensis Kiaersk.]; Árvore; Sc: VCS 30127

Eugenia burkartiana (D. Legrand) D. Legrand; Árvore; Sc: ESA, OTA 1364

Eugenia candolleana DC.; Árvore; Sc: OTA 1355

Eugenia capitulifera O. Berg; Árvore; Sc: ESA, 6

Eugenia cerasiflora Miq.; Árvore; Sc: ESA/SPSF/SP, 6

Eugenia cereja D. Legrand; Árvore; Sc: ESA, 6

Eugenia copacabanensis Kiaersk.; Árvore; Sc: ESA

Eugenia cuprea (O. Berg) Nied.; Árvore; Sc: ESA, 8

Eugenia florida DC.; Árvore; Sc: ESA, 6

Eugenia handroana D. Legrand; Árvore; Sc: ESA

Eugenia involucrata DC.; Árvore; Sc: 6, OTA 1382

Eugenia magnibracteolata Mattos \& D.Legrand; Árvore; Sc: VCS 29329

Eugenia melanogyna (D. Legrand ) Sobral; Árvore; Sc: 6, VCS 30133

Eugenia mosenii (Kausel) Sobral; Árvore; Sc: ESA/SPSF/SP

Eugenia multicostata D. Legrand; Árvore; Sc: ESA, RAFL 445

Eugenia neoglomerata Sobral [= E. glomerata Spring ex Mart.]; Árvore; Sc: ESA, 6

Eugenia neoverrucosa Sobral [= E. verrucosa D. Legrand]; Árvore; Sc: ESA, 4, 5

Eugenia oblongata O. Berg; Árvore; Sc: ESA/SPSF, 8

Eugenia platysema O. Berg; Árvore; Sc: VCS 30157

Eugenia prasina O. Berg [= E. stictosepala Kiaersk.]; Árvore; Sc: ESA, 6

Eugenia pruinosa D. Legrand; Árvore; Sc: 6, VCS 29326

Eugenia riedeliana O. Berg; Árvore; Sc: VCS 30161

Eugenia subavenia O. Berg; Árvore; Sc: ESA/SPSF/SP, 6

Eugenia subterminalis DC. [= Calycorectes psidiiflorus (O. Berg) Sobral]; Árvore; Sc: ESA

Eugenia supraaxillaris Spring [= E. cambucarana Kiaersk.]; Árvore; Sc: ESA, 6

Eugenia ternatifolia Cambess [= E. beaurepaireana (Kiaersk.) D. Legrand].; Árvore; Sc: ESA, 4, 5, 6, OTA 1363

Eugenia umbelliflora O. Berg; Árvore; Sc: 6, 8, OTA 1381

Eugenia verticillata (Vell.) Angely [= E. schuechiana O. Berg]; Árvore; Sc: VCS 30159

Eugenia viridiflora Cambess.; Árvore; Sc: ESA/SP/RB

Eugenia xiriricana Mattos; Árvore; Sc: VCS 30163

Marlierea eugeniopsoides (Kausel \& D. Legrand) D. Legrand.; Árvore; Sc: ESA/SPSF/SP, 6, 7 
Família, espécie e autoria [sinonímia]

Marlierea excoriata Mart. [= M. parviflora O. Berg]; Árvore; Sc: ESA, 6

Marlierea obscura O. Berg; Árvore; Sc: ESA, 2, 4, 5, 6, 8

Marlierea racemosa (Vell.) Kiaersk.; Árvore; Sc: 4, 5

Marlierea reitzii D. Legrand; Árvore; Sc: SPSF/SP

Marlierea suaveolens Cambess.; Árvore; Sc: ESA, 7, VCS 30184

Marlierea tomentosa Cambess.; Árvore; Sc: ESA/UEC/SP, 8

Myrceugenia campestris (DC.) D. Legrand \& Kausel; Árvore; Sc: SPSF/SP, RAFL 466

Myrceugenia glaucescens (Cambess.) D. Legrand \& Kausel; Árvore; Sc: 6, OTA 1365

Myrceugenia kleinii D. Legrand \& Kausel; Árvore; Sc: 6, VCS 29340

Myrceugenia myrcioides (Cambess.) O. Berg; Árvore; Sc: ESA/SPSF/SP, 6

Myrceugenia pilotantha (Kiaersk.) Landrum; Árvore; Sc: VCS 30196

Myrceugenia seriatoramosa (Kiaersk.) D. Legrand \& Kausel; Árvore; Sc: OTA 1354

Myrceugenia venosa D.Legrand; Árvore; Sc: MO

Myrcia richardiana (O. Berg) Kiaersk.; Árvore; Sc: ESA

Myrcia aff. racemosa (O. Berg) Kiaersk.; Árvore; Sc: OTA 1398

Myrcia anacardiifolia Gardner [= Gomidesia anacardiifolia (Gardner) O. Berg]; Árvore; Sc: ESA/SPSF, 7, 8

Myrcia brasiliensis Kiaersk. [= Gomidesia schaueriana O. Berg]; Árvore; Sc: OTA 1366

Myrcia flagellaris (D. Legrand) Sobral [= Gomidesia flagellaris D. Legrand]; Árvore; Sc: ESA, 8

Myrcia guianensis (Aubl.) DC.; Árvore; Sc: OTA 1378

Myrcia hatschbachii D. Legrand; Árvore; Sc: ESA/SPSF

Myrcia hebepetala DC. [= Gomidesia affinis (Cambess.) D. Legrand]; Árvore; Sc: RB

Myrcia heringii D. Legrand; Árvore; Sc: ESA, OTA 1373, 1404

Myrcia ilheosensis Kiaersk. [= Gomidesia fenzliana (Gardner) O. Berg]; Árvore; Sc: 4, 5, OTA 1367

Myrcia macrocarpa DC.; Árvore; Sc: ESA, OTA 1409

Myrcia multiflora (Lam.) DC.; Árvore; Sc: ESA

Myrcia pubipetala Miq. [= M. grandiflora (O. Berg) D. Legrand]; Árvore; Sc: ESA/SPSF, 6

Myrcia sp.; Árvore; Sc: OTA 1397

Myrcia spectabilis DC. [= Gomidesia spectabilis (DC.) O. Berg]; Árvore; Sc: ESA, 2, 8

Myrcia splendens (Sw.) DC. [= M. fallax (Rich.) DC., M. formosiana DC., M.rostrata DC.]; Árvore; Sc: SPSF/RB

Myrcia tenuivenosa Kiaersk.; Árvore; Sc: 4, 5, VCS 30199

Myrcia tijucensis Kiaersk. [= Gomidesia tijucensis (Kiaersk.) D. Legrand.]; Árvore; Sc: VCS 30174

Myrciaria floribunda (West ex Willd.) O. Berg; Árvore; Sc: ESA, OTA 1399

Myrciaria sp.; Árvore; Sc: OTA 1400

Neomitranthes glomerata (D. Legrand) D. Legrand; Árvore; Sc: ESA

Neomitranthes obscura (DC.) N. Silveira; Árvore; Sc: RAFL 268, 269

Pimenta pseudocaryophyllus (Gomes) Landrum; Árvore; Sc: OTA 1356

Plinia complanata M. L. Kawas. \& B. Holst; Árvore; Sc: ESA, 6, OTA 1403

Plinia pseudodichasiantha (Kiaersk.) G.M.Barroso ex Sobral [= P. pauciflora M.L. Kawas. \& B. Holst]; Árvore; Sc: ESA, 6

Psidium cattleianum Sabine; Arbusto; Sc: ESA/SP, 4

Psidium myrtoides O. Berg [= Psidium myrsinoides O.Berg]; Árvore; Sc: RB

Siphoneugena densiflora O. Berg; Árvore; Sc: SP, 7

\section{NYCTAGINACEAE}

Guapira opposita (Vell.) Reitz; Árvore; Sc: UEC/SPSF, 2, 4, 5, 6, 8, VCS 30217 
Lima, R.A.F. et al.

Apêndice 1. Continuação...

Família, espécie e autoria [sinonímia]

Pisonia ambigua Heimerl; Árvore; Sc: VCS 30226

OCHNACEAE (inclui Quiinaceae)

Ouratea multiflora (Pohl) Engl.; Árvore; Sc: ESA

Ouratea parviflora (A. DC.) Baill.; Árvore; Sc: ESA

Quiina glazovii Engl.; Árvore; Sc: 4, 5, VCS 29241

Quiina magallano-gomesii Schwacke; Árvore; Sc: 6, OTA 1375, 1405

Sauvagesia erecta L.; Erva; Sc: SPSF

OLACACEAE

Heisteria silvianii Schwacke; Árvore; Sc: 4, 5, VCS 29324

Tetrastylidium grandifolium (Baill.) Sleumer; Árvore; Sc: VCS 29255, 30231

OLEACEAE

Chionanthus filiformis (Vell.) P.S.Green [= C. mandioccana (Eichler) Lozano \& Fuertes]; Árvore; Sc: 2, 4, 6, OTA 1361

ONAGRACEAE

Fuchsia regia (Vell.) Munz; Epífito; Sc: UEC/SPSF

Ludwigia octovalvis (Jacq.) P.H. Raven; Erva; Sc: SPSF

OPILIACEAE

Agonandra excelsa Griseb.; Árvore; Sc: OTA 1352

OXALIDACEAE

Oxalis cytisoides Mart. ex Zucc.; Erva; Sc: NY

Oxalis hirsutissima Mart. ex Zucc.; Erva; Sc: SP

PASSIFLORACEAE

Passiflora alata Curtis; Liana; Sc: NY

Passiflora amethystina J.C. Mikan; Liana; Sc: ESA

Passiflora jilekii Wawra; Liana; Sc: SPSF

Passiflora loefgrenii Vitta; Liana; Sc: ESA

PENTAPHYLLACACEAE

Ternstroemia brasiliensis Cambess.; Árvore; Sc: UEC

PHYLLANTHACEAE

Hieronyma alchorneoides Allemão; Árvore; Sc: ESA/SPSF/SP, 2, 4, 6, 7, 9

Phyllanthus niruri L. [= P. lathyroides Kunth]; Erva; Sc: RB

Phyllanthus stipulatus (Raf.) G.L. Webster; Erva; Sc: ESA/UEC

PHYTOLACCACEAE

Gallesia integrifolia (Spreng.) Harms; Árvore; Sc: 1

Phytolacca dioica L.; Árvore; Sc: SPSF, VCS 29206

Seguieria americana L. [= S. floribunda Benth.]; Arbusto/liana; Sc: SPSF

PICRAMNIACEAE

Picramnia gardneri Planch.; Árvore; Sc: RB, RAFL 480

Picramnia glazioviana Engl.; Árvore; Sc: 1

Picramnia ramiflora Planch.; Arbusto; Sc: 6, VCS 30333

PIPERACEAE

Manekia obtusa (Miq.) T. Arias, Callejas \& Bornst.; [= Sarcorhachis obtusa (Miq.) Trel.] epífito; Sc: TBB 429

Ottonia macrophylla ssp. tuberculata Kunth; Arbusto; Sc: SPSF

Peperomia alata Ruiz \& Pav.; Epífito; Sc: TBB 608 
Família, espécie e autoria [sinonímia]

Peperomia catharinae Miq.; Epífito; Sc: TBB 431

Peperomia corcovadensis Gardner; Epífito; Sc: TBB 414

Peperomia glabella (Sw.) A.Dietr.; Epífito; Sc: SPSF

Peperomia obtusifolia (L.) A.Dietr.; Epífito; Sc: TBB 680

Peperomia pereskiifolia (Jacq.) Kunth; Epífito; Sc: TBB 432

Peperomia pseudoestrellensis C. DC.; Epífito; Sc: ESA

Peperomia rhombea Ruiz \& Pav.; Epífito; Sc: ESA

Peperomia rotundifolia (L.) Kunth; Epífito; Sc: SPSF, TBB 426

Peperomia subternifolia Yunck.; Epífito; Sc: ESA

Peperomia tetraphylla (G.Forst.) Hook. \& Arn.; Epífito; Sc: SPSF

Peperomia urocarpa Fisch. \& C.A.Mey.; Epífito; Sc: TBB 481

Piper aduncum L.; Arbusto; Sc: SPSF, 6

Piper amplum Kunth; Arbusto; Sc: RB

Piper arboreum Aubl.; Arbusto; Sc: ESA

Piper bowiei Yunck.; Arbusto; Sc: ESA

Piper caldense C. DC.; Erva; Sc: ESA, 6

Piper cernuum Vell. [= P. gigantifolium C.DC.]; Árvore; Sc: RAFL 483

Piper chimonanthifolium Kunth; Arbusto; Sc: SPSF, 6

Piper dilatatum Rich.; Arbusto; Sc: RB, RAFL 485

Piper gaudichaudianum Kunth; Arbusto; Sc: ESA/SPSF/UEC

Piper mollicomum Kunth; Erva; Sc: SPSF

Piper mosenii C. DC.; Arbusto; Sc: ESA/SPSF

Piper pseudopothifolium C. DC.; Arbusto; Sc: 6, RAFL 487

Piper rivinoides Kunth; Arbusto; Sc: RB

Piper setebarraense E.F.Guim. \& L.H.P.Costa; Arbusto; Sc: SPSF, RAFL 488

Piper solmsianum C. DC.; Arbusto; Sc: RAFL 489

Piper umbellatum L. [= Pothomorphe umbellata (L.) Miq.]; Arbusto; Sc: RAFL 318

\section{PLANTAGINACEAE}

Scoparia dulcis L.; Erva; Sc: SPSF

Stemodia trifoliata (Link) Rchb.; Erva; Sc: UEC/SPSF

Stemodia vandellioides (Benth.) V.C. Souza; Erva; Sc: UEC/SPSF

\section{POLYGALACEAE}

Polygala paniculata L.; Erva; Sc: SPSF

Securidaca lanceolata A. St.-Hil. \& Moq.; Liana; Sc: ESA

\section{POLYGONACEAE}

Coccoloba alnifolia Casar.; Árvore; Sc: VCS 29296

Coccoloba fastigiata Meisn.; Árvore; Sc: 4, VCS 29249

Coccoloba glaziovii Lindau; Árvore; Sc: VCS 29295, 30238

Polygonum acuminatum Kunth; Erva; Sc: ESA/SPSF

Ruprechtia laxiflora Meisn.; Árvore; Sc: 4, 8

PRIMULACEAE (inclui Myrsinaceae)

Ardisia guianensis (Aubl.) Mez [= A. handroi Toledo ex Handro, Stylogyne pauciflora Mez]; Arbusto; Sc: UEC/SPSF/IAC, 4, 5, 6 
Lima, R.A.F. et al.

Apêndice 1. Continuação...

Família, espécie e autoria [sinonímia]

Cybianthus peruvianus (A. DC.) Miq. [= Conomorpha peruviana A.DC.]; Arbusto; Sc: UEC/IAC, 6, OTA 1362

Myrsine coriacea (Sw.) Roem. \& Schult. [= M. ferruginea (Ruiz \& Pavón) Sprengel, Rapanea ferruginea (Ruiz \& Pav.) Mez]; Árvore; Sc: SPSF/IAC, 4, 5

Myrsine gardneriana A.DC. [= Rapanea gardneriana (A. DC.) Mez]; Árvore; Sc: SPSF/IAC, 2, 6

Myrsine guianensis (Aubl.) Kuntze [= Rapanea guianensis Aubl.]; Árvore; Sc: 1

Myrsine hermogenesii (Jung-Mend. \& Bernacci) M.F.Freitas [=Rapanea hermogenesii Jung-Mend. \& Bernacci]; Árvore; Sc: 6, VCS 30124

Myrsine umbellata Mart. [= Rapanea umbellata (Mart.) Mez, R. acuminata Mez]; Árvore; Sc: UEC/SPSF, 2, 4, 5, 6

Stylogyne laevigata (Mart.) Mez [= Ardisia martiana Miq.]; Árvore; Sc: VCS 30124

PROTEACEAE

Euplassa legalis (Vell.) I. M. Johnst.; Árvore; Sc: 1

Roupala montana var. brasiliensis (Klotzsch) K. Edwards; Árvore; Sc: 4, 5, 6, 8, VCS 29240

Roupala sculpta Sleumer; Árvore; Sc: ESA, OTA 1384

ROSACEAE

Prunus myrtifolia (L.) Urb. [= P. sellowii Koehne]; Árvore; Sc: ESA/SPSF/IAC, 2, 4

Rubus brasiliensis Mart.; Liana; Sc: SPSF

Rubus rosifolius Sm. var. rosifolius; Arbusto; Sc: SPSF

Rubus urticifolius Poir.; Liana; Sc: SPSF

RUBIACEAE

Alseis floribunda Schott; Árvore; Sc: SPSF, 4, 5, 8, VCS 29315

Amaioua intermedia Mart. ex Schult. \& Schult.f. [ A. guianensis Aubl.] ; Árvore; Sc: ESA/SPSF, 4, 5, 6

Bathysa australis (A. St.-Hil.) K. Schum. [ B. meridionalis L.B. Sm. \& Downs]; Árvore; Sc: SPSF/IAC, 2, 4, 5, 6, 8, 9

Borreria alata (Aubl.) DC.; Erva; Sc: ESA/SPSF

Borreria capitata (Ruiz \& Pav.) DC.; Erva; Sc: ESA

Borreria palustris (Cham. \& Schltdl.) Bacigalupo \& E.L.Cabral; Erva; Sc: SPSF

Borreria remota (Lam.) Bacigalupo \& E.L. Cabral; Erva; Sc: SPSF

Borreria verticillata (L.) G.Mey.; Erva; Sc: SPSF

Chomelia brasiliana A. Rich.; Arbusto; Sc: RB

Chomelia parvifolia (Standl.) Govaerts [= C. catharinae (L.B. Sm. \& Downs) Steyerm.]; Arbusto; Sc: UEC/SPSF/IAC, 6, VCS 30254

Chomelia pedunculosa Benth.; Árvore; Sc: VCS 30257

Coccocypselum cordifolium Nees \& Mart.; Erva; Sc: ESA

Coccocypselum geophiloides Wawra [= C. krauseanum Standl.]; Erva; Sc: SPSF

Coccocypselum hasslerianum Chodat [= C. cordatum Krause]; Erva; Sc: IAC

Coccocypselum lanceolatum (Ruiz \& Pav.) Pers.; Erva; Sc: SPSF

Cordiera concolor (Cham.) Kuntze [= Alibertia concolor (Cham.) K. Schum.]; Arbusto; Sc: SPSF

Cordiera myrciifolia (K. Schum.) C.H. Perss. \& Delprete [= Alibertia myrciifolia K. Schum.]; Arbusto; Sc: 6, VCS 30249

Coussarea contracta (Walp.) Müll. Arg.; Árvore; Sc: 6, VCS 30259

Coutarea hexandra (Jacq.) K. Schum.; Arbusto; Sc: SPSF

Emmeorhiza umbellata (Spreng.) K. Schum.; Liana; Sc: SPSF

Faramea montevidensis (Cham. \& Schltdl.) DC.; Árvore; Sc: VCS 29288, 30261

Faramea multiflora A. Rich.; Arbusto; Sc: RAFL 495

Galianthe brasiliensis (Spreng.) E.L.Cabral \& Bacigalupo; Erva; Sc: SPSF

Galium hypocarpium (L.) Endl. ex Griseb; Liana; Sc: SPSF 
Flora do Parque Estadual Carlos Botelho

Apêndice 1. Continuação...

Família, espécie e autoria [sinonímia]

Geophila repens (L.) I.M. Johnst.; Erva; Sc: SPSF

Hillia illustris (Vell.) K. Schum.; Epífito; Sc: TBB 575

Hillia parasitica Jacq.; Epífito; Sc: IAC/HRCB

Ixora brevifolia Benth. [ I. membranacea Müll. Arg.]; Árvore; Sc: ESA

Ixora burchelliana Müll. Arg.; Árvore; Sc: RAFL 345

Ixora gardneriana Benth. [= Ixora heterodoxa Müll. Arg.]; Árvore; Sc: VCS 29283, 29294

Manettia pubescens Cham. \& Schltdl.; Liana; Sc: UEC

Margaritopsis cymuligera (Müll. Arg.) C.M.Taylor [= Psychotria birotula L.B. Sm. \& Downs]; Arbusto; Sc: RAFL 498

Margaritopsis chaenotricha (DC.) C.M. Taylor [= Psychotria chaenotricha DC.]; Arbusto; Sc: IAC

Palicourea marcgravii A. St.-Hill.; Árvore; Sc: SPSF

Posoqueria acutifolia Mart.; Árvore; Sc: UEC, 4, 6

Posoqueria latifolia (Rudge) Schult.; Árvore; Sc: SPSF/IAC, 5

Psychotria brachypoda (Müll. Arg.) Britton [= P. umbellata Vell.]; Arbusto; Sc: IAC, VCS 29243

Psychotria forsteronioides Müll. Arg. [= P. malaneoides Müll. Arg.]; Arbusto; Sc: ESA/SPSF/IAC, 6

Psychotria leiocarpa Cham. \& Schltdl.; Arbusto; Sc: ESA

Psychotria mapourioides DC.; Árvore; Sc: SPSF/IAC

Psychotria nemorosa Gardner; Arbusto [= P. pubigera Schltdl.]; Sc: SPSF/IAC, VCS 30270, 30271

Psychotria nuda (Cham. \& Schltdl.) Wawra; Árvore; Sc: 5

Psychotria stachyoides Benth.; Erva; Sc: 4, 5

Psychotria suterella Müll. Arg.; Arbusto; Sc: ESA/SPSF/IAC, 2, 4, 5, 6

Psychotria vellosiana Benth. [= P. sessilis (Vell.) Müll. Arg.]; Árvore; Sc: UEC/SPSF/IAC, 4, 5

Randia ferox (Cham. \& Schltdl.) DC. [ Randia armata (Sw.) DC.]; Árvore; Sc: ESA/UEC/IAC

Rudgea jasminoides (Cham.) Müll. Arg.; Árvore; Sc: UEC/SPSF, 4, 5, 8, VCS 30301

Rudgea recurva Müll. Arg.; Árvore; Sc: SPSF/IAC, VCS 30304

Sabicea villosa Willd. ex Schult.; Liana; Sc: SPSF

Simira corumbensis (Standl.) Steyerm.; Árvore; Sc: VCS 30315

Sphinctanthus sp.; Árvore; Sc: VCS 29209

\section{RUTACEAE}

Esenbeckia grandiflora Mart. subsp. grandiflora; Árvore; Sc: UEC/SPSF, 4, 5, 6, OTA 1407

Pilocarpus pauciflorus A. St.-Hil.; Árvore; Sc: ESA

Zanthoxylum rhoifolium Lam.; Árvore; Sc: ESA/SPSF/SPF, 4, 5, 8

\section{SABIACEAE}

Meliosma sellowii Urb. [= M. glaziovii Urb., M. sinuata Urb.]; Árvore; Sc: SPSF, OTA 1401, 1402

Meliosma aff. sellowii Urb.; Árvore; Sc: OTA 887, 1353

\section{SALICACEAE}

Casearia decandra Jacq.; Árvore; Sc: UEC/SPSF, 4, 5, 6

Casearia obliqua Spreng.; Árvore; Sc: ESA/IAC, 4, 6

Casearia sylvestris Sw.; Árvore; Sc: UEC/IAC, 4, 5, 6, 7, 8

Xylosma ciliatifolia (Clos) Eichler; Arbusto; Sc: 4

Xylosma glaberrima Sleumer; Árvore; Sc: VCS 29226

Xylosma tweediana (Clos) Eichler [= X. pseudosalzmannii Sleumer]; Árvore; Sc: 4, 5

\section{SANTALACEAE}

Phoradendron falcifrons (Hook. \& Arn.) Eichler; Hemiparasita; Sc: ESA 
Lima, R.A.F. et al.

Apêndice 1. Continuação...

Família, espécie e autoria [sinonímia]

Phoradendron fragile Urb.; Parasita; Sc: SPSF, TBB 1072

SAPINDACEAE

Allophylus edulis (A. St.-Hil., Cambess. \& Juss.) Radlk.; Árvore; Sc: SPSF

Allophylus petiolulatus Radlk.; Arbusto; Sc: 4, 5, 6, 8, VCS 29314

Cupania oblongifolia Mart.; Árvore; Sc: UEC/SPSF, 2, 4, 5, 6, 8

Cupania vernalis Cambess.; Árvore; Sc: SPSF, 4, 5

Cupania zanthoxyloides Cambess.; Árvore; Sc: ESA/RB

Dodonaea viscosa Jacq.; Arbusto; Sc: ESA

Matayba guianensis Aubl.; Árvore; Sc: SPSF, 6

Matayba intermedia Radlk.; Árvore; Sc: SPSF, VCS 29308

Matayba sp. inédita [ M. juglandifolia (Cambess.) Radlk.]; Árvore; Sc: 4, 5, 6, 8, VCS 29270

Paullinia carpopoda Cambess.; Liana; Sc: SPSF

Paullinia meliifolia Juss.; Liana; Sc: UEC, 2

Paullinia trigonia Vell.; Liana; Sc: ESA/SPSF, 2

Serjania communis Cambess.; Liana; Sc: SPSF

SAPOTACEAE

Chrysophyllum flexuosum Mart.; Árvore; Sc: SPSF, 5, 8, VCS 30320

Chrysophyllum gonocarpum (Mart. \& Eichler) Engl.; Árvore; Sc: 4, 5, 8

Chrysophyllum inornatum Mart.; Árvore; Sc: VCS 30325

Chrysophyllum viride Mart. \& Eichl.; Árvore; Sc: 4, 5, 7, 8, VCS 29201

Diploon cuspidatum (Hoehne) Cronquist; Árvore; Sc: 6, VCS 29300

Ecclinusa ramiflora Mart.; Árvore; Sc: 5, 6, VCS 30328

Micropholis crassipedicellata (Mart. \& Eichler) Pierre; Árvore; Sc: SPSF, 4, 5, 7, 9

Pouteria bullata (S. Moore) Baehni; Árvore; Sc: ESA, 6

Pouteria caimito (Ruiz \& Pav.) Radlk.; Árvore; Sc: 6, VCS 30330

Pouteria psammophila (Mart.) Radlk.; Árvore; Sc: RAFL 815

Pouteria torta (Mart.) Radlk.; Árvore; Sc: ESA, 5

Pouteria venosa (Mart.) Baehni; Árvore; Sc: SPSF, 4, 5, 8

Pradosia lactescens (Vell.) Radlk.; Árvore; Sc: VCS 29322

Sideroxylon obtusifolium (Roem \& Schult.) T.D. Penn.; Árvore; Sc: ESA

SCHLEGELIACEAE

Schlegelia parviflora (Oerst.) Monach. [= S. ramizii Sandwith]; Epífito; Sc: UEC/SPSF, TBB 543

SCROPHULARIACEAE

Buddleja stachyoides Cham. \& Schltdl.; Erva; Sc: ESA/SPSF

SOLANACEAE

Acnistus arborescens (L.) Schltdl.; Árvore; Sc: SPSF

Aureliana fasciculata (Vell.) Sendtn.; Arbusto; Sc: ESA/SPSF/UEC

Brunfelsia pauciflora (Cham. \& Schltdl.) Benth.; Arbusto; Sc: UEC

Capsicum recurvatum (Witasek) Hunz.; Arbusto; Sc: 6, VCS 30334

Cestrum bracteatum Link \& Otto [= Cestrum amictum Schltdl.]; Arbusto; Sc: ESA/SPSF

Cestrum intermedium Sendtn.; Arbusto; Sc: SPSF

Cestrum schlechtendalii G. Don; Arbusto; Sc: ESA

Dyssochroma viridiflora (Sims) Miers; Epífito; Sc: ESA/UEC, TBB 1104

Sessea brasiliensis Toledo; Arbusto; Sc: 1 
Família, espécie e autoria [sinonímia]

Solanum argenteum Dunal; Árvore; Sc: SPSF

Solanum bullatum Vell.; Árvore; Sc: EAS, OTA 1390

Solanum cinnamomeum Sendtn. [=Solanum excelsum A. St.-Hil.]; Árvore; Sc: SPSF, 4, 5, 6

Solanum concinnum Schott ex Sendtn.; Árvore; Sc: IAC

Solanum mauritianum Scop.; Arbusto; Sc: 1, 5

Solanum megalochiton Mart.; Arbusto; Sc: SPSF

Solanum melissarum Bohs [= Cyphomandra divaricata (Mart.) Sendtn.]; Arbusto; Sc: VCS 29234

Solanum piluliferum Dunal; Arbusto; Sc: RAFL 183

Solanum pseudoquina A. St.-Hil. [= S. inaequale Vell.]; Árvore; Sc: SPSF, 4, 5

Solanum ramulosum Sendtn.; Arbusto; Sc: SPSF

Solanum rufescens Sendtn.; Arbusto; Sc: ESA, 4, 5

Solanum schwackei Glaz.; Arbusto; Sc: RAFL 557

Solanum swartzianum Roem. \& Schult.; Árvore; Sc: ESA/SPSF, 7

Solanum vaillantii Dunal; Arbusto; Sc: ESA

Solanum variabile Mart.; Arbusto; Sc: SPSF/IAC

Solanum wacketii Witasek; Arbusto; Sc: ESA

\section{STYRACACEAE}

Styrax acuminatus Pohl; Árvore; Sc: UEC

\section{SYMPLOCACEAE}

Symplocos celastrinea Mart.; Árvore; Sc: 4, 5, 8, OTA 1391

Symplocos falcata Brand.; Árvore; Sc: OTA 1347

Symplocos glandulosomarginata Hoehne; Árvore; Sc: SPSF

Symplocos laxiflora Benth.; Árvore; Sc: ESA/SPSF

Symplocos variabilis Mart.; Árvore; Sc: SPSF, OTA 1386

THEACEAE

Laplacea fruticosa (Schrad.) Kobuski [= Gordonia fruticosa (Schrad.) H. Keng]; Árvore; Sc: ESA THYMELAEACEAE

Daphnopsis schwackeana Taub. [ D. gemmiflora (Miers) Domke]; Árvore; Sc: OTA 1349

\section{URTICACEAE}

Boehmeria caudata Sw.; Arbusto; Sc: ESA/SPSF

Cecropia glaziovii Snethl.; Árvore; Sc: 5, 6, VCS 30020

Cecropia pachystachya Trécul; Árvore; Sc: 1

Coussapoa microcarpa (Schott) Rizzini; Árvore/ hemi-epífito; Sc: 4, 5, 6, VCS 30021

Pilea cf. rhizobola Miq.; Erva; Sc: ESA

Pourouma guianensis Aubl. [= P. acutiflora Trécul]; Árvore; Sc: VCS 29202

Urera baccifera (L.) Gaudich. ex Wedd.; Arbusto; Sc: ESA/SPSF

Urera nitida (Vell.) Brack; Arbusto; Sc: ESA/SPSF

\section{VALERIANACEAE}

Valeriana scandens L.; Liana; Sc: UEC/SPSF

\section{VERBENACEAE}

Citharexylum myrianthum Cham.; Árvore; Sc: VCS 30339 
Lima, R.A.F. et al.

Apêndice 1. Continuação...

\section{Família, espécie e autoria [sinonímia]}

Lantana trifolia L.; Arbusto; Sc: ESA

Stachytarpheta cayennensis (Rich.) Vahl; Erva; Sc: UEC

Stachytarpheta polyura Schauer; Erva; Sc: ESA

Verbena rigida (L.) Spreng.; Erva; Sc: IAC

VIOLACEAE

Amphirrhox longifolia (A. St.-Hil.) Spreng.; Arbusto; Sc: UEC

Anchietea pyrifolia (Mart.) G. Don.; Liana; Sc: SPSF/IAC

Noisettia orchidiflora (Rudge) Ging.; Erva; Sc: ESA

VITACEAE

Cissus stipulata Vell.; Liana; Sc: ESA/SPSF

VOCHYSIACEAE

Vochysia selloi Warm.; Árvore; Sc: ESA

Vochysia cf. bifalcata Warm.; Árvore; Sc: OTA 1379

\section{WINTERACEAE}

Drimys brasiliensis Miers [= D. winterii Forst.]; Árvore; Sc: SPSF, 4, 5, 6

Apêndice 2. Espécies excluídas da lista de espécies do PECB e o respectivo motivo de exclusão. Sc = Fonte. Ver Apêndice 1 para legendas das fontes. Appendix 2. Species excluded from the PECB species list and the respective motive of exclusion. Sc = Source. See Appendix 1 for source legends.

\section{Família, espécie e autoria}

ACANTHACEAE

Thunbergia alata Bojer ex Sims; Sc: ESA; Motivo: exótica

ANACARDIACEAE

Astronium sp.; Sc: 9; Motivo: ocorrência duvidosa

APIACEAE

Foeniculum vulgare Mill.; Sc: ESA; Motivo: exotica

AQUIFOLIACEAE

Ilex ebenacea Reissek; Sc: 5; Motivo: identificação duvidosa

ARACEAE

Anthurium emines Schott; Sc: MO; Motivo: identificação duvidosa

Anthurium lancea Sodiro; Sc: ESA; Motivo: ocorrência duvidosa

ARALIACEAE

Schefflera calva (Cham.) Frodin \& Fiaschi; Sc: ESA; Motivo: identificação duvidosa

ARAUCARIACEAE

Araucaria angustifolia (Bertol.) Kuntze; Sc: 1; Motivo: introduzida

ASTERACEAE

Vernonia organensis ?; Sc: HRCB; Motivo: nome desconhecido

BALSAMINACEAE

Impatiens walleriana Hook. f.; Sc: ESA; Motivo: exótica

BERBERIDACEAE

Nandina domestica Thunb.; Sc: ESA; Motivo: introduzida

BIGNONIACEAE

Adenocalymma redactum A.H. Gentry; Sc: 2; Motivo: nome desconhecido

Adenocalymma trifoliatum (Vell.) R.C. Laroche; Sc: ESA; Motivo: ocorrência duvidosa

Tabebuia avellanedae Lorentz ex Griseb.; Sc: 5; Motivo: ocorrência duvidosa

BROMELIACEAE

Bromelia ornata ?; Sc: ESA; Motivo: nome desconhecido 
Flora do Parque Estadual Carlos Botelho

Apêndice 2. Continuação...

Família, espécie e autoria

Guzmania lingulata (L.) Mez; Sc: NY; Motivo: ocorrência duvidosa

\section{CACTACEAE}

Rhipsalis baccifera (J.M. Muell.) Stearn; Sc: ESA/SPSF; Motivo: identificação duvidosa

CALOPHYLLACEAE

Calophyllum brasiliense Cambess; Sc: 1; Motivo: introduzida

CELASTRACEAE

Hylenaea praecelsa (Miers) A.C. Sm.; Sc: MOBOT; Motivo: ocorrência duvidosa

Maytenus alaternoides Reissek; Sc: SPSF, 5, 8, 7; Motivo: identificação duvidosa

Maytenus distichophylla Mart.; Sc: 4, 5; Motivo: ocorrência duvidosa

Maytenus ilicifolia Mart. ex Reissek; Sc: ESA; Motivo: identificação duvidosa

\section{COMBRETACEAE}

Combretum sp.; Sc: 4; Motivo: ocorrência duvidosa

Terminalia brasiliensis (Cambess. ex A.St.-Hil.) Eichler; Sc: 5; Motivo: identificação duvidosa

\section{CUCURBITACEAE}

Sechium edule Sw.; Sc: ESA; Motivo: introduzida

\section{CUNONIACEAE}

Weinmannia pinnata L.; Sc: ESA/SPSF; Motivo: ocorrência duvidosa

CYATHEACEAE

Alsophila nitida Kunze ex Ettingsh.; Sc: 4, 5; Motivo: ocorrência duvidosa

DRYOPTERIDACEAE

Elaphoglossum ornatum (Mett. ex Kuhn) H.Christ; Sc:; Motivo: ocorrência duvidosa

FABACEAE

Dalbergia cf. foliolosa Benth.; Sc: 6; Motivo: identificação duvidosa

Eriosema glaziovii Harms; Sc: SPSF; Motivo: ocorrência duvidosa

Inga affinis DC.; Sc: 2; Motivo: ocorrência duvidosa

Inga alba (Sw.) Willd.; Sc: 2; Motivo: ocorrência duvidosa

Inga fagifolia $\mathrm{G}$. Don; Sc: RB; Motivo: ocorrência duvidosa

Inga vera (DC.) T.D. Penn.; Sc: 1; Motivo: introduzida

Myroxylon balsamum (L.) Harm.; Sc: ESA, 5, 7; Motivo: identificação duvidosa

Myroxylon peruiferum L. f.; Sc: 4, 5; Motivo: identificação duvidosa

Pterocarpus violaceus Vogel; Sc: SPSF/UEC, 4, 5; Motivo: identificação duvidosa

\section{GENTIANACEAE}

Macrocarpaea glaziovii Gilg.; Sc: SPSF; Motivo: ocorrência duvidosa

IRIDACEAE

Crocosmia crocosmiiflora (Lenoine ex. Morren) N.E. Brown; Sc: ESA; Motivo: exótica

\section{LACISTEMATACEAE}

Lacistema hasslerianum Chodat; Sc: ESA; Motivo: ocorrência duvidosa

\section{LAURACEAE}

Aiouea trinervis Meisn.; Sc: ESA; Motivo: ocorrência duvidosa

Nectandra micranthera Rohwer; Sc: SPSF; Motivo: ocorrência duvidosa

Ocotea minarum (Nees) Mez; Sc: ESA/SPSF; Motivo: ocorrência duvidosa

Persea americana Mill.; Sc: ESA; Motivo: introduzida

MELASTOMATACEAE

Leandra raddii Mart. ex DC.; Sc: ESA/SPSF; Motivo: identificação duvidosa

MELIACEAE

Trichilia hirta L.; Sc: ESA; Motivo: ocorrência duvidosa

Trichilia pallida Sw.; Sc: ESA; Motivo: ocorrência duvidosa

MUSACEAE

Musa ornata Roxb.; Sc: ESA; Motivo: exótica

MYRTACEAE

Campomanesia adamantium (Cambess.) O. Berg; Sc: 7; Motivo: identificação duvidosa 
Lima, R.A.F. et al.

Apêndice 2. Continuação...

Família, espécie e autoria

Myrceugenia miersiana (Gardner) D. Legrand \& Kausel; Sc: ESA; Motivo: identificação duvidosa

Myrceugenia scutellata D. Legrand; Sc: ESA; Motivo: identificação duvidosa

Myrcia variabilis DC.; Sc: SPSF, 7; Motivo: identificação duvidosa

NYCTAGINACEAE

Neea sp.; Sc: 8; Motivo: identificação duvidosa

Torrubia sp.; Sc: 9; Motivo: identificação duvidosa

ORCHIDACEAE

Campylocentrum minus Fawc. \& Rendle; Sc: SPSF; Motivo: ocorrência duvidosa

Epidendrum miersii Lindl.; Sc: ESA; Motivo: identificação duvidosa

POLYGONACEAE

Coccoloba latifolia Lam.; Sc: 5; Motivo: ocorrência duvidosa

Coccoloba martii Meisn. [= C. marginata Benth.]; Sc: 6; Motivo: ocorrência duvidosa

Triplaris americana Loefl. ex L.; Sc: SPSF; Motivo: introduzida

POLYPODIACEAE

Polypodium pectinatum L.; Sc: SPSF; Motivo: identificação duvidosa

PRIMULACEAE (inclui Myrsinaceae)

Ardisia cauliflora Mart. \& Miq.; Sc: 4, 5; Motivo: identificação duvidosa

RUBIACEAE

Alibertia macrophylla K. Schum.; Sc: ESA; Motivo: ocorrência duvidosa

Chomelia barbellata Standl.; Sc: 2; Motivo: ocorrência duvidosa

Rudgea blanchettiana Müll. Arg.; Sc: ESA, 5, 8; Motivo: identificação duvidosa

RUTACEAE

Zanthoxylum fagara (L.) Sarg.; Sc: ESA; Motivo: ocorrência duvidosa

SALICACEAE

Xylosma salzmanii (Clos.) Eichler; Sc: 5; Motivo: nome desconhecido

SAPINDACEAE

Cupania emarginata Cambess.; Sc: 2; Motivo: identificação duvidosa

Matayba elaeagnoides Radlk.; Sc: 4, 5, 8; Motivo: identificação duvidosa

SAPOTACEAE

Pouteria gardneriana (A. DC.) Radlk.; Sc: 5; Motivo: identificação duvidosa

Pouteria laurifolia Radlk.; Sc: SPSF; Motivo: identificação duvidosa

Pouteria macrophylla (Lam.) Eyma; Sc: ESA; Motivo: ocorrência duvidosa

Pouteria ramiflora (Mart.) Radlk.; Sc: 4; Motivo: ocorrência duvidosa

Sideroxylon gardnerianum (Mart. \& Eichl.); Sc: 4, 7, 9; Motivo: identificação duvidosa

SOLANACEAE

Solanum erianthum D. Don; Sc: 5; Motivo: ocorrência duvidosa

SYMPLOCACEAE

Symplocos neglecta Brand; Sc: SPSF; Motivo: identificação duvidosa

WOODSIACEAE

Deparia petersenii (Kunze) M. Kato; Sc: SPSF; Motivo: exótica

ZINGIBERACEAE

Hedychium coronarium J. König; Sc: ESA; Motivo: exótica 